\title{
Narrativas del conflicto y construcciones del pasado entre los q'eqchi'es: del relato de vida al mito
}

Conflict narratives and reconstructions of the past among the Q'eqchi': from life stories to myths

Narrations du conflit et constructions du passé chez les Q'eqchi' : du récit de vie au mythe

\section{Agnès Bergeret}

\section{OpenEdition}

\section{Journals}

Edición electrónica

URL: http://journals.openedition.org/jsa/15474

DOI: $10.4000 /$ jsa. 15474

ISSN: $1957-7842$

Editor

Société des américanistes

Referencia electrónica

Agnès Bergeret, « Narrativas del conflicto y construcciones del pasado entre los q'eqchi'es: del relato de vida al mito ", Journal de la société des américanistes [En línea], Maya times | 2017, Publicado el 31 diciembre 2017, consultado el 01 mayo 2019. URL : http://journals.openedition.org/jsa/15474 ; DOI 10.4000/jsa. 15474 


\title{
Narrativas del conflicto y construcciones del pasado entre los q'eqchi'es: del relato de vida al mito
}

\author{
Agnès BERGERET*
}

\begin{abstract}
En este artículo, se estudia la relación de los q'eqchi'es de Cahabón (Alta Verapaz, Guatemala) con diferentes tiempos del pasado a través de la dinámica de dos grandes categorías de géneros narrativos: "las historias" establecidas sobre los antepasados y "lo padecido", narrativas más autobiográficas que cuentan sufrimientos individuales en tiempos recientes. El análisis de una narrativa sobre la lucha jurídica y política de un líder campesino q'eqchi' contra la Hacienda, contada a la etnógrafa y comparada con la versión de un ladino, pone de relieve las innovaciones del narrador para crear, a partir de los diferentes géneros narrativos, un héroe que permita dar sentido a los trastornos históricos recientes. [Palabras claves: memoria colectiva, guerra interna guatemalteca, latifundio, maya q'eqchi', ladino.]
\end{abstract}

Conflict narratives and reconstructions of the past among the Q'eqchi': from life stories to myths. This article studies how the Q'eqchi' of Cahabón (Alta Verapaz, Guatemala) relate to different past times, by examining the dynamics of two broad categories of narrative genre: established "stories" about ancestors and more autobiographical narratives about individual "suffering" experienced in recent times. The analysis of a narrative on a Q'eqchi' peasant's legal and political struggle against the Hacienda, recounted to the ethnographer and compared with the version of a ladino, shows the innovations of the narrator, as he uses different narrative genres to create a hero who can give meaning to recent historical upheavals. [Key words: collective memory, civil war, latifundio, Q'eqchi' Maya, ladino.]

Narrations du conflit et constructions du passé chez les Q'eqchi' : du récit de vie au mythe. Cet article étudie la relation que les Q'eqchi' de Cahabón (Alta Verapaz, Guatemala) entretiennent avec différents temps du passé, par l'examen de la dynamique de deux grandes catégories de genres narratifs : les "histoires" établies sur les ancêtres et les récits plus autobiographiques autour des "souffrances" individuelles vécues dans des temps récents. L'analyse d'un récit sur la lutte juridique et politique d'un leader paysan q'eqchi' contre l'Hacienda, raconté à l'ethnographe

* PACTE, Université Grenoble-Alpes, 14 avenue Marie Reynoard, 38100 Grenoble [agnes.bergeret@free.fr]. 
et comparé à la version d'un ladino, met en évidence les innovations du narrateur pour créer, à partir des différents genres narratifs, un héros qui puisse donner du sens aux bouleversements historiques récents. [Mots-clés : mémoire collective, guerre civile, latifundio, maya q'eqchi', ladino.]

Este artículo intentará destacar la relación que mantienen los q'eqchi'es de Cahabón con diferentes tiempos del pasado, tomando como punto de partida algunos relatos ${ }^{1}$ y situándolos en la dinámica del sistema de sus géneros narrativos. Lo que definimos aquí como un género narrativo es, entre los géneros discursivos, un acto de palabra codificado, con una forma y un contenido socialmente estabilizados en un momento histórico dado ${ }^{2}$, y cuya especificidad radica en el hecho de que construye una intriga ${ }^{3}$ (Ricœur 1983-1984; Veynes 1971). Entre la multiplicidad de elementos que se puede estudiar dentro de un género, estudiaremos aquí tres dimensiones que expresan esta relación con el pasado. La primera es el estatuto social del género narrativo: su contexto extra-verbal, es decir los lugares, momentos, situaciones institucional y socialmente diferenciadas en los que puede pronunciarse. Entra aquí la diferencia entre narrativas públicas, que sean establecidas o debatidas, y aquellas íntimas, a lo máximo familiares, que no benefician de un espacio colectivo de discusión. La segunda dimensión es el punto de vista del narrador: la selección de los protagonistas de la historia y su papel narrativo y discursivo ${ }^{4}$, los anclajes temporales y el contenido temático. La tercera dimensión es la intriga o trama narrativa ${ }^{5}$ : los eventos que subraya, el proceso que reconstituye, así como los modos de legitimación y de moralización respecto a los actos de los personajes.

Los géneros narrativos de una sociedad forman un sistema y se imponen al locutor $^{6}$. Éste debe escoger el género adecuado en cada situación de narración, pero puede conformarse o innovar con ciertas reglas de los géneros. Así, el locutor juega con los géneros para explicitar su mundo actual operando un trabajo dinámico socio-cognitivo sobre las orientaciones genéricas de sus palabras (Adam y Heidmann 2009, p. 13). De hecho una conversación con una

1. "El tiempo se vuelve humano en la medida en que es articulado en un modo narrativo" (Ricœur 1985, p. 17).

2. "Un discours est un acte de parole. [...] Le genre est la codification historique attestée de propriétés discursives" (Todorov 1978, p. 51).

3. Enfocamos en la dimensión de la intriga como elemento caracterizador de la narración. La intriga se define como la "dinámica integradora", la "síntesis [...] de acontecimientos, causas, oportunidades, etc. dentro de la unidad temporal de una acción total y completa" (Ricœur 1983, p. 11; 1984, p. 18). Por otra parte, Veynes (1971, p. 46-47) propuso considerar todo trabajo histórico como una puesta en intriga.

4. Nos inspiramos aquí del método propuesto por Rabatel (1997), quien distingue los puntos de vista del narrador y del personaje.

5. Inspirándonos aquí de Propp (1970).

6. Para retomar Bakhtine 1984. 
etnógrafa extranjera es típicamente una situación en la que se puede (o debe) jugar con las normas si se le quiere explicar el pasado ${ }^{7}$.

Basándonos en las prácticas locales, distinguimos dos grandes categorías de géneros narrativos q'eqchi'es (en un enfoque similar al de GutierrezEstevés 1998): la categoría $e b$ ' li seeraq' ("las historias") y la categoría $l i$ xk'ulmank ("lo padecido"). Sin embargo, no se puede estudiar el sistema de las narrativas q'eqchi'es fuera de las narrativas que existen entre los ladinos que viven en el mismo territorio ${ }^{8}$ : aquellas familias mestizas (en su mayoría descendientes de españoles), hispanohablantes, constituyen el $2 \%$ de la población cahabonera. Son grandes propietarios, administradores de fincas, o se dedican a actividades comerciales, administración pública y educación. Las narrativas q'eq'chi'es y ladinas se construyen en interrelación, con constantes circulaciones, re-interpretaciones y traducciones.

En este artículo, llevaremos a cabo un análisis en cuatro etapas de la relación de los q'eqchi'es con el tiempo. Examinaremos primero la categoría eb'li seeraq' y los diferentes géneros que la componen. Dichos géneros describen, explican y permiten entender la relación con la tierra cahabonera a partir de las aventuras de los antepasados, al tiempo que fijan ciertos eventos y reglas sociales en la memoria. De manera comparativa, destacaremos los diferentes géneros que usan los ladinos para describir su relación con el territorio. En la segunda parte, describiremos, dentro del género más autobiográfico de $l i$ $x k$ 'ulmank, las narrativas que evocan el periodo del "gran sufrimiento" (li nim rahilal), es decir el tiempo de la guerra interna guatemalteca (1960-1996) . En la tercera parte analizaremos más detenidamente el ejemplo singular del relato por Martín ${ }^{10}$ de la lucha jurídica y política de su abuelo Marcelino Xol contra la Hacienda. Esta lucha por librarse del trabajo forzado y obtener tierras corresponde a la cara local del conflicto nacional. Estudiando sus diferencias y convergencias con los géneros narrativos de "las historias" y de "lo padecido",

7. En este caso, se trataba de un trabajo de campo de doctorado (Bergeret 2012) cuyo propósito inicial era la comprensión de las instituciones actuales del trabajo y de la comercialización agricolas q'eqchi'es. Influenciado por las narrativas de los actores, el estudio se amplió al conflicto histórico por las tierras.

8. El municipio de Cahabón cuenta con más de 66.000 personas (proyecciones del INE para 2016), entre los cuales el 95\% son mayas-q'eqchi' y el $2 \%$ son ladinos. Los q'eqchi'es son uno de los veintiún pueblos mayas de Guatemala. Hoy en día, viven en una larga zona incluyendo las Verapaces, Izabal y Petén (es decir todo el centro-este y el norte de Guatemala). Representan más de 850.000 personas en Guatemala. Son el primer grupo en Guatemala en cuanto a la proporción de personas hablando el idioma materno indígena (84\%).

9. Fueron 36 años de guerra entre el regimen militar y guerrillas que desembocaron en la muerte de más de 250.000 personas. La comisión de esclarecimiento estima que el ejército, las comisiones militaires, la patrullas de autodefensa civil y los escuadrones de la muerte fueron responsables por lo menos del 88\% de las muertes (ODHAG-REHMI 1998, p. 389).

10. Todos los nombres son seudónimos, a excepción de Marcelino Xol. 
observaremos la estrategia de Martín para construir un héroe que se fije en la "memoria colectiva" Amílcar acerca de la saga familiar de los Champney, los mayores propietarios de Cahabón, a quienes se enfrentó Marcelino Xol. Comparando sus puntos de vista y tramas narrativas pondremos de relieve las especificidades de las lecturas del conflicto de tierras propuestas en cada relato.

\section{Las "historias" de Cahabón}

\section{Eb’ li seeraq'. Estatuto social y punto de vista}

Entre los q'eqchi'es, la palabra seeraq' designa discursos que, podríamos decir, guardan algún parecido con el cuento, la leyenda, la historia, la conversación, la plática (ALMG 2004, p. 165). Se usa en particular cuando uno recuerda una narrativa colectivamente establecida y la comparte con otra(s) persona(s) en un ambiente de alegría y tranquilidad. Estas "historias" son exclusivamente orales ${ }^{12}$. Las pronuncian más bien de noche, en general padres de familia o ancianos, ya sea durante veladas rituales q'eqchi'es, ya sea después de la cena, con el objetivo de explicar a los niños una práctica. También nos fueron contadas durante largas caminatas. Por fin, pueden asimismo ser difundidas por la radio local en programas que integran entrevistas a ancianos.

Estas "historias" obedecen a convenciones estrictas, y se encuentran regularidades en sus intrigas, personajes y motivos. El narrador adopta el punto de vista más neutro y ausente posible, con un saber ilimitado en cuanto a la historia, como si la historia existiera independientemente del él: se expresa como un mensajero, transmitiendo con deferencia una palabra sagrada. Se expresan los sentimientos de los personajes, y se usa mucho el estilo directo para relatar pensamientos; también tienen cabida diálogos entre personajes cuya índole es distinta de la del narrador (animales, antepasados, Tzuultaq'a-espíritus de las

11. Recordamos la definición de la memoria colectiva que da Nora (1978, p. 398): "el conjunto de los recuerdos, conscientes o no, de una experiencia vivida y/o mitificada por una colectividad". En el caso maya, nos inspiramos de los trabajos alrededor de los "modelos mayas de la interpretación del cambio histórico" (Vapnarsky 2001, p. 184), cada evento histórico siendo transformado por los mitos en un encuentro telescópico de tiempos, según una visión cíclica (Bricker 1981, p. 6). Expresan que el mundo sigue diseñado según esquemas llamados "antiguos" (propios, autónomos), que los extranjeros o colonizadores no han logrado hacer desaparecer, enseñando que los extranjeros sólo son intrusos cuya acción siempre será rechazada (en la introducción de Menget y Molinié, en Becquelin y Molinié 1993, p. 13).

12. Se está actualmente construyendo otro género con la recolección de historias transcritas en q'eqchi', publicadas en libros, por especialistas (mayas, ladinos o extranjeros) de la cultura maya-q'eqchi'. Valoran un territorio extenso en Alta Verapaz y Petén uniendo el pueblo q'eqchi', muchas veces retomando el símbolo de las "trece montañas". 
montañas). Se habla de un tiempo muy lejano, pero a la vez, se siente proximidad y actualidad: estas historias fundamentan reglas actuales.

Las "historias" tienen como marco espacios amplios: relieves montañosos, fuentes, ríos, cuevas y rocas, vegetales, animales y hombres. El territorio se vuelve enteramente vivo: las montañas forman entre sí una familia, están pobladas de vegetales y animales hablantes a los que se considera como su cultivo o ganado. En cuanto a la intriga, no resaltan actos aislados sino largas secuencias que corresponden a aventuras de héroes, y que integran diálogos entre entidades heterogéneas, así como metamorfosis, y viajes entre cielo, tierra y mundo subterráneo. Dichas historias no tienen "moraleja", pero terminan en general con frases de conclusión que fundamentan ciertas reglas: guían las prácticas de cultivo o de ayuno, las preparaciones culinarias, los rituales de la cofradía. Así, los personajes no son "buenos" ni "malos". Los únicos sentimientos que aparecen son el miedo, la aceptación o el enojo, respecto a la transgresión de fronteras territoriales, ofrendas al Tzuultaq'a o reglas matrimoniales.

Entre los q'eqchi'es de Cahabón, todas estas "historias" constituyen una práctica para afirmar su pertenencia a una misma cultura "territorializada" alrededor de su gran montaña-valle (Tzuultaq'a) Qana Itzam así como las demás montañas más pequeñas que se encuentran dentro del municipio. Adoptan una visión del tiempo que se presenta como un continuo reemplazo, como si distintos tiempos se sustituyeran entre sí (véase la contribución de Paul Kockelman 2017, en esta publicación), en mecanismos de rotaciones de "cargos", de intercambio mutual de servicios y de pagos ceremoniales que aseguran la continuidad del mundo. Su reproducción sigue modelos de analogías entre macrocosmos y microcosmos, los rituales permitiendo actualizar la generosidad del señor del macrocosmo hacia cada comunidad y cada familia.

En la categoría de las "historias", hemos decidido interesarnos por unos géneros que revelan anclajes temporales muy diversos. Este amplio conjunto incluye un primer género de las "palabras sagradas" (loq'laj aatin) o palabras con "valor, verdad, poder, utilidad, bien" (xloq'al) (ALMG 2008, p. 227). Ciertas de estas "historias" se acercan a lo que llamaríamos mitos fundadores. Describen "el principio del mundo": Montañas-Valles crean el cielo, el día y la noche, los animales y los hombres. Aquí presentamos algunos ejemplos de dichas "historias". Entre estas, destaca una narrativa acerca de una madre devorada que fundamenta el tabú del parricidio y del canibalismo, pero que más que todo hace hincapié en la obligación del "dar de comer", recalcando la complementariedad entre el cazador y su esposa, y la relación entre padres e hijos (Chirix li yohob'k, Cuz 2001, p. 60-62). Otra es "El robo de la hija de Xukaneb"13 que describe el rapto de una prometida, cuyo novio abandonado "encierra" consecuentemente todos los

13. Narrativa recogida por Burkitt (The Hills and the Corn, 1917-1920), actualizado por el Padre Darío Caal Xi (Ak’ kutan 1999, p. 28-34) 
alimentos en la montaña. Otra es la muy conocida "El Sol y la Luna", que nos servirá en la sección siguiente para ilustrar nuestro análisis de este sub-género.

Las "palabras sagradas" siempre cuentan con la mención de los tiempos del "origen", ya sea al inicio del relato: "Sa' mayer kutan, toj maji winq kiyo'la chi ruchich 'och' -En los tiempos remotos, cuando aun no había hombres nacidos en esta tierra" (El Sol y la Luna, Estrada Monroy 1990, p. 108-141), ya sea en su fin: 'Jo 'ka'in naq kisiyaak chaq li na'leb' rik'ineb' li qaxe' qatoon. Ab'an a'in, moko yal aatin ta chi jo 'kan, wan b'an xloq'al-Así es cómo germinaron las ideas de nuestros antepasados. Pero no son palabras comunes, tienen su sacralidad" (Chirix li yohob'k, Cuz 2001, p. 60-62).

Al lado de las "palabras sagradas", existen lo que llamaremos leyendas, ya que están ancladas en momentos históricos claves (en particular el periodo colonial), y que describen milagros realizados por un personaje, diseñando una situación modelo, digna de admiración. Así, la leyenda "Cómo Qana Itzam termina con las conquistas" (Cruz Torres 1978, p. 99-106) explica el fracaso de la invasión por los españoles en la región de las Verapaces gracias a la intervención de un quetzal cuya cola, tal una fina piedra de obsidiana, se vuelve un arma terrible, así como los telares de mujeres atacando con Qana Itzam.

Otras "historias" no tienen anclaje temporal específico. Se parecen a fábulas cortas que movilizan una pareja (o más) de animales - entre los cuales uno es en realidad el Tzuultaq 'a, el espíritu de la montaña. Los cuentos "oximbil", término que designa la introducción de un hombre dentro de la montaña, fundamentan las ceremonias de ofrenda al Tzuultaq'a que cualquier hombre tiene que ofrecer, al entrar en un territorio, para pedir permiso de realizar cultivos, cazar o pescar. También son relatos a-históricos. No evocan acontecimientos fundadores, sino que permiten el "mantenimiento" de las reglas a lo largo del tiempo. Suelen empezar así: 'Sa' jun kutan, naxye li seraaq' aatin chi jo'ka 'in, kiko jun laj kar chi re li ha' Pelizilpek-Un día, dice esta historia, un pescador fue hacia el río Pelizilpek" (Oximbil del pescador, narrado por Martín, Bergeret 2012, p. 637-639).

En otras historias que nos fueron contadas no son los Tzuultaq'a los protagonistas, sino los Chol Winq y los Aj Q'eq. Los cuentos de Chol Winq narran encuentros entre personas q'eqchi'es y los hombres “salvajes" -sin bautizar, tienen características de animales y viven en las montañas. Aunque nunca sea explícito, estos personajes hacen referencia a los choles, pueblo que resistió a la evangelización (al contrario de los q'echi'es) y fueron aniquilados por los españoles. La particularidad de los cuentos sobre los Aj Qeq radica en que se refieren específicamente al tiempo de las Haciendas (las grandes propiedades cafetaleras nacidas a finales del siglo XIX, y desaparecidas en las décadas 1960 y 1970, que usaron como mano de obra a los "colonos", es decir a los habitantes q'eqchi'es que vivían en su predio) y permiten explicar el enriquecimiento de los propietarios. Gracias a libros del principio del siglo xx (Danien 2005), podemos observar que el Aj Q'eq, la figura de trickster 
que caracteriza dichos cuentos, ha pasado de ser una criatura híbrida entre el hombre y el mono, que trastornaba las relaciones entre mujeres y hombres, a una mezcla con la vaca (símbolo de la Hacienda). Sus acciones consisten desde aquel entonces en robar y vigilar a los colonos, poniéndose al servicio de las grandes propiedades: "Todas las Haciendas poseían su $\mathrm{Aj} Q$ 'eq", nos comentaron los q'eqchi'es. Incluso dicen que "los negritos llegaron a Cahabón cuando los alemanes llegaron con sus vacas" (Carlos, Tzalamtun).

\section{Tramas narrativas de "las historias" q'eqchi'es}

Para ilustrar la dinámica narrativa de "las historias", nos apoyaremos de manera contrastiva en la intriga de la narrativa del Sol y de la Luna, que nos contó un joven de Cahabón; dicha narrativa correspondió a la primera parte de la larga serie de Sol y Luna (o Balamk'e y Po'), la cual es muy conocida, e incluso admite varias versiones (Estrada Monroy 1990, Cruz Torres 1978, entre otras). Cruz Torres (1978) sigue con los episodios del adulterio con Nube, la muerte de Nube y Luna, el renacimiento de Luna, y la subida al cielo de Sol y Luna. Los análisis de estos relatos han sido muy importantes en los últimos años (Braakhuis 2010; Van Akkeren 2000; Kockelman 2007). Ya que esta palabra sagrada concentra una serie de motivos muy representativos de lo que se encuentra en otras "historias", la escogimos como una narrativa de referencia para presentar las similitudes y variaciones alrededor de una trama relativamente compartida. Se resume la intriga en el recuadro 1.

1. Intrusión: el cazador Sol entra en el territorio del Señor Montaña-Valle y de su hija Luna.

2. Intentos de seducción por disimulación: Sol usa una piel de venado para que Luna crea que es buen cazador (fracaso); pide prestadas las plumas del colibrí (éxito).

3. Transgresión: huida de la hija Luna con Sol; rabia del Señor.

4. Persecución por un sicario y huida: persecución hasta el mar por el sicario (el tío relámpago).

5. Sanción: muerte de Luna.

6. Pago ritual: trabajo de Sol para el Señor Montaña-Valle (en la versión de Cruz Torres 1978).

7. Renacimiento gracias a un hechicero benévolo: las libélulas (hechiceros benévolos) juntan la sangre de Luna en las tinajas; después de trece días, Luna renace con nueva apariencia femenina.

8. Validación: apertura del sexo de Luna (paso encima del cuerpo, por diferentes animales según las versiones).

9. Nueva configuración: Luna se vuelve esposa de Sol.

Recuadro 1 - Resumen de la primera parte del cuento "El Sol y la Luna". 
En esta primera trama, cabe subrayar la dinámica narrativa que se encuentra en la gran mayoría de "las historias": intrusión en un territorio $\rightarrow$ robo (aquí el rapto de la hija) $\rightarrow$ sanción mortal. El robo como evento central atestigua de la relación paradigmática de los q'eqchi'es con el territorio propiedad del Tzuultaq'a, celoso de cualquier intrusión desprovista de reconocimiento o reciprocidad hacia él. El robo se define como la apropiación de una cosa sin haberle pedido permiso a su dueño. Ahora bien, por lo general, en las "historias" cahaboneras, no se trata de un ladrón introduciéndose de noche en una casa, sino de un personaje usando disfraces en pleno día. Aquí, el sol logra seducir a la luna cuando pide prestadas las plumas al colibrí. Este motivo del disfrazmetamórfosis se encuentra en varias otras "historias", así como motivos de escondites y de señuelos: siempre se trata de engañar al otro con otra apariencia.

La sanción puede transformarse en perdón y por lo mismo, provocar nuevos trastornos. Así, en la narrativa "el robo de la hija de Xukaneb", el padre perdona al "ladrón", lo que provoca el enojo del prometido oficial. Como sanción del robo de su prometida, "cierra" las montañas y provoca una hambruna.

La secuencia siguiente (secuencia 6 del recuadro 1) enseña que la transgresión castigada se puede remediar si uno cumple con las obligaciones de respeto, ofrendas y trabajo hacia el dueño. Esta etapa de pago ritual es el acmé de los cuentos oximbil (que se apoyan también en el esquema intrusión $\rightarrow$ robo $\rightarrow$ sanción), ya que el hombre tiene que realizar la ofrenda al Tzuultaq'a para restablecer las relaciones equilibradas, para ser rescatado, y para poder salir de la montaña. Después tiene que explicar durante tres días a sus hermanos lo que sufrió por haber transgredido la regla, y muere.

En la secuencia 7, el ser sacrificado puede renacer gracias a un hechicero benévolo que recompone la unidad de su cuerpo. En otras narrativas, al contrario, puede desempeñar esta función de ayudante un hechicero destructor que restablece la situación. Así se resuelve "el robo de la hija de Xukaneb”, por ejemplo, cuando se encuentra al personaje adecuado (dotado de cualidades específicas) para vencer al responsable de la hambruna: en este caso, un personaje capaz de "abrir" la montaña donde se ha encerrado el maíz.

Los cuentos de encuentro con los Chol Winq tratan de la intrusión de los hombres en los espacios de la selva y la montaña. Uno, por ejemplo, relata el rapto en un camino de una mujer envidiosa, su unión forzada con un Chol Winq, el nacimiento de niños "animales", un rescate y la sanción (la muerte de la mujer envidiosa). Contrastando con los ejemplos precedentes, los cuentos con los $A j Q^{\prime} e q$ ilustran la inversión del esquema convencional de sanción ya que instauran cierta forma de reciprocidad: en general se trata de encerrar y golpear a un negrito, para amansarlo y que se conforme en robar a los pobres en favor de su rico dueño. Dichos cuentos atestiguan de una etapa de trastorno en la dinámica narrativa de "las historias", acarreada por la irrupción del tiempo 
histórico de las Haciendas: integran a personajes antiguos en una nueva configuración, invirtiendo los valores.

\section{El género ladino del cuento}

Los ladinos de Cahabón tienen su propio sistema narrativo y sus propias versiones de la relación con el territorio cahabonero. Dentro de este sistema, el género narrativo del "cuento", se comparte en familia y con amigos, y ahora, también se escribe y publica en libros. Los cuentos ladinos ponen en escena oposiciones sociales y morales muy claras, con las cuales el interlocutor puede identificarse. Basándonos en una compilación de cuentos editada por un maestro ladino jubilado (Argueta 2005, para todos los ejemplos a continuación), notamos que el punto de vista del narrador puede ser borrado, neutro, pero que en la gran mayoría de los casos, los cuentos se presentan al contrario como una anécdota personal o que le haya pasado a una persona muy cercana. Plantean una experiencia extraordinaria en un contexto "histórico". "El fantasma de Sepamac" (p. 47-57) -una de las fincas de los Champney, los mayores propietarios históricos de Cahabón- transcurre en la época de las Haciendas (a la que los ladinos llaman "época de las fincas"). "El brujo y el guardián del potrero" (p. 134-137) tiene lugar durante el desarrollo de la actividad ganadera, a partir de los años 1960. "El brujo que era militar" (p. 146-155) se desarrolla durante la campaña contra-insurgente en oposición a las guerrillas de los años 1960 a 1980. Estos cuentos suelen hablar de los q'eq'chi'es de manera despectiva y patronal: se refieren a ellos como a los "pobres q'eqchi'es", los "mozos", la "peonada" (p. 47), que "en su pobreza, al fin y al cabo... ¡ ieran felices!" (p. 51), o evocan a los "alumnos con su carita campesina, humilde y que se sonríen con nosotros" (p. 124). Presentan un entorno despolitizado: no mencionan ni conflicto ni luchas colectivas, ni tampoco a un grupo "malo" frente a un grupo "bueno", sino a individuos con cierta actitud moral, calificada de buena o mala.

Al lado de los personajes social e históricamente identificables, dichos cuentos incluyen a personajes típicos de la cultura mestiza en todo Guatemala y más allá, como el duende, la llorona, la simanagua, el cadejo, el negrito, etc. Estos cuentos presentan muchas historias sobre los "brujos" de Cahabón, personajes misteriosos y amenazantes, que tienen intenciones precisas, en particular de venganza. El cuento se centra en un episodio de hechicería (transformación en animal o en piedra, sumisión de un animal salvaje, muerte de una persona a causa de una "enfermedad" monstruosa, etc.) en lugares muy específicos del territorio cahabonero, configurados ya sea por la propiedad privada, ya sea por la naturaleza, pero nunca por las aldeas q'eqchi'es (p. 134-137, p. 156-162). El autor siempre precisa las circunstancias en las que la historia le fue contada. En "la leyenda del pujuyero y del quetzal" (p. 92-102), un brujo es quien cuenta la "historia" a un ladino. Estos cuentos ponen de realce una visión de la relación ladino-q'eqchi', 
que asigna a los q'eqchi'es la identidad de hombres pobres, sometidos, discretos, entre los cuales se encuentran personajes con poderes sobrenaturales.

No aparecen héroes, sino personajes muy comunes enfrentando actos de magia. Entre los ladinos, los cuentos traducen la visión de un territorio compartido entre dos grupos con diferencias marcadas - el suyo portador de una civilización, de la educación, de la administración municipal, de la plantación de café, de buenas prácticas religiosas (con las estatuas de los santos), de la constitución de un centro urbano agradable. El autor expresa también su cariño hacia esta tierra descrita por la belleza de su naturaleza, y en la cual ya tienen raíces. Se destacan las relaciones laborales y las alianzas entre ladinos y ciertos amigos q'eqchi'es “amantes del progreso" hacia el desarrollo (p. 120), así como los intercambios culturales con ellos: así, retoma ciertos motivos de "las historias" q'eqchi'es para señalar sus amistades con este grupo, el conocimiento de sus tradiciones y creencias y el reconocimiento de sus poderes.

\section{"Lo padecido"}

Las narrativas del registro de "lo padecido" (la traducción literal de li xk'ulmank es "lo que fue recibido") ocurren en situaciones cotidianas, cuando uno quiere contar lo que le pasó personalmente, a una persona familiar, o a una persona identificada, en un tiempo más o menos cercano. Al contrario de "las historias" que se narran en un ambiente agradable, estos relatos vuelven sobre el proceso que llevó a un problema, con sentimientos de sufrimiento, pesar y angustia. Se cuentan con un punto de vista interno, subjetivo (desde su propio punto de vista si es anécdota autobiográfica o desde el punto de vista del protagonista - en general un amigo o un familiar que le contó la anécdota en primera persona al narrador presente). Expresan la incomprensión de una situación descontrolada: transcriben sorpresas, confusión, oscuridad. Estos relatos empiezan o terminan a menudo con una frase de tipo ' $A$ ' an a 'in $x k$ ' $u l$ mank -esto fue recibido". K'ulmank significa ser recibido, pasar, padecer, ser sufrido. Viene del verbo $k^{\prime} u l u k$ que se traduce por recibir, ir al encuentro. No se trata de explicar una regla o la forma del mundo, sino de solicitar al interlocutor para informarle, para ganarse su apoyo, o para que participe a la resolución del problema.

Dentro de este género, queremos aquí observar las narrativas que tratan del conflicto interno guatemalteco. Son mucho menos institucionalizadas que las "historias" o que "lo padecido" relativo a temas como un accidente de tráfico, una enfermedad, o un conflicto familiar, laboral o de vecindad. En ellas es recurrente la expresión " $a$ 'an a in li rahilal xqak'ul chaq-esto es el sufrimiento que recibimos", la cual se ha de vincular con la expresión del "gran sufrimiento" (li nim rahilal) usada entre los q'eqchi'es para designar 
la guerra que entre los años 1960 y 1990 opuso al regimen militar con las guerrillas comunistas. Traumas que no se curan hasta hoy -mientras sigue la impunidad de los crímenes, a nivel nacional como local-y conflictos internos a familias y comunidades -surgidos a raíz de la guerra y de los que es difícil hablar- dificultan la emergencia de espacios sociales estabilizados en los que se puedan contar dichas narrativas.

Así, cuando uno pregunta a los habitantes q'e'chi'es de Cahabón sobre el pasado en las aldeas, nunca se menciona el conflicto armado: los relatos siempre se insertan dentro de una temporalidad más larga, y se inician con el hecho de que "toda" 14 la tierra de Cahabón pertenecía a una sola persona, el señor Champney. Para obtener relatos más detallados sobre la Hacienda de Champney, tuvimos que solicitarlos explícitamente. Sin embargo, los ancianos se veían muy felices de compartir sus recuerdos, y concluían lamentando que los jóvenes no les pidieran testimonios de manera más seguida. Por su lado, los jóvenes escuchaban con gran atención cuando entrevistábamos a un anciano. Resultaba claro que si bien existía de ambos lados un afán por compartir dichas historias, faltaban los lugares y momentos adecuados y regulados para su expresión.

En cuanto a la memoria de la violencia, rara vez surge, encerrada en el miedo de reactivar el conflicto y la "tristeza" ( $r$ li ch'ool) que ha provocado. Se cuentan historias del pasado en la intimidad de los hogares, raramente con vecinos o con la comunidad en su conjunto. Sin embargo, cabe subrayar que estos recuerdos, aunque no se expresen de manera formal en lo cotidiano, siempre se tienen presentes e influyen significativamente en las decisiones y discusiones que surgen en las reuniones comunales del domingo. Es necesario un dispositivo particular para que se activen las palabras sobre el tema: sin embargo, una vez la confianza asegurada, se desencadenan. Trabajos escolares y universitarios (Paredes 2006) así como trabajos de "memoria" (Huet 2006) constituyen unos de los espacios para la formalización de estas palabras íntimas en palabras públicas y colectivas. De esta manera, en una aldea, pudimos observar la expresión colectiva de los acontecimientos del conflicto armado principalmente bajo dos formas: obras de teatro imaginadas por jóvenes estudiantes a partir de los relatos de sus padres; y discusión colectiva, por la noche, con la etnógrafa-cada participante presentando un relato de lo que había vivido. En ambos casos, un maestro había organizado los eventos y encuentros, y solicitado la venida del extranjero para propiciar un momento especial. El extranjero-testigo servía de tercero neutro y catalizador que favorecía la expresión de estas palabras.

14. En realidad, toda la parte oriental del municipio actual formaba parte de la propiedad del estadounidense Champney, mientras la parte occidental contaba tres grandes propiedades alemanas. 
Así, en la gran mayoría de los casos, las narrativas de "lo padecido" sobre la guerra no tienen dimensión colectiva ni comunitaria. Los silencios no permiten que se forje y estabilice una trama, sobre la cual se pueda debatir.

\section{Una narración q'eqchi de la lucha por la tierra}

Cabe evocar por lo tanto cómo el tiempo de la guerra irrumpió en el curso de nuestro trabajo etnográfico. Una mañana del año 2005, estábamos grabando varias "historias" cahaboneras con Martín. Este hombre de unos cuarenta y cinco años es terapeuta (combina múltiples medicinas) y locutor de la radio católica; su trabajo periodístico sobre la vida cultural y política local era reconocido por todos. Habíamos tenido la oportunidad de encontrarnos unas semanas antes en la sede de la radio: él había propuesto que grabáramos unas de las palabras sagradas, fábulas y oximbil protagonizadas por Qana Itzam u otros Tzuultaq'a -narrativas que le gustaba contar por la radio y que según él, debían de corresponder a lo que quería escuchar una etnógrafa. De hecho, nos convenía colectar narrativas actuales que trataran de la relación de los q'eqchi'es con su territorio. A las 13 horas, mientras terminábamos la entrevista dándole las gracias, Martín dijo: "Bien, ahora que te he contado todo esto, tengo que hablarte de mi abuelo". Se trataba de Marcelino Xol, uno de los líderes campesinos más importantes de la región.

Así fue cómo la lucha por la tierra -versión local del conflicto armado nacional- entró en nuestra investigación. Los relatos pertenecientes al género de las "historias" -en el contexto particular de esta conversación con una etnógrafa extranjera- no cumplían cabalmente con el deseo de Martín de explicar los fundamentos de la vida q'eqchi. Tenía que recurrir a este relato de "lo padecido". Nos parece interesante apoyarnos aquí en este testimonio (reproducido y traducido en el recuadro 2), ya que la singularidad y la calidad narrativa de una sola historia de vida puede aclarar las relaciones de una sociedad con su memoria, incluso si este ejemplo representa una excepción. Relata cómo Marcelino, "colono" obligado a trabajar en los cafetales de los Champney, emprendió, a causa de los abusos a los que le sometían, una lucha jurídica por el pago del trabajo en los años 1940, exigió tierras en los años 1960, y fue asesinado a principios de los años 1970.

De aquí en adelante, nos dedicaremos al análisis de la relación de los q'eqchi'es con este tiempo de la historia reciente, resaltando el vínculo que puede haber entre el relato de Martín y la dinámica narrativa de las "historias" presentadas anteriormente. Comparando el relato de Martín con narrativas de otros q'eqchi'es, podremos percibir cómo los narradores adoptan estrategias variadas según el significado que quieran dar al conflicto de tierras, y cómo Martín da cierta inflexión a la dinámica narrativa, creando, con voz militante, un género narrativo híbrido, que irrumpe entre las formas de palabras institucionalizadas en las aldeas. 
1. Tinye aawe: kiwank jun linmama', linabuelito, li xk'ab'a Marcelino Xol. Junxil chaq kutank, arin Chi K'ajb'om, xwan li asyent sa' chi junil li wan arin Chi K'ajb'om.

2. Li kristiaan, li qas qitzin, aanilasinb'ileb', minb'ileb' chi k'anjelak chi majun, ink'axtojb 'ileb'. Jo'ka'an li loq'laj kutank, junxil, neke'ok chi k'anjelak li kristiaan se'waqib' hoor re q'ela toj waqib' hoor re ewu.

3. Sa junxil chaq kutank, más chaq li rahilal a'in Chi K'ajb'om, aran Sepacuyte, chi junil Chi K'ajb'om, chi junil li na'ajej, chi junil a'aneb' li k'aleb'aal, chi junil b'oqb'il'eb' sa'li k'anjel.

4. Wankeb' li china ka'ch'in, wankeb' lajeb' chihab', naq taqlanb'il chi k'anjelak. Xb'aan naq a'an li xk'a'uxl li patrón Champney, renaq che'xtrab'ajiq.

5. Ma wank junaq li ixq, maak'a' xb'elom, tento naq te'xsik' li $x$ b'elom, tento naq twanq li $x b$ 'elom ink'a naru maak'a'li xb'elom.

6. Yo chi nume'k li kutank, ut ink'a ke 'b'ileb' li xch 'iich' re li k'anjelak, re li kristiaan neke'xu'wak xb'aan maak'a' li k'aru reeb', ne'b'a'eb' li kristiaan.

7. Eb'li po 're ixaqil xe'aj a las dos de la mañana, tres de la mañana, xb'aan naq tub'tu li wa porque neke'xik chi k'anjelak. Ilaq chaq, chalen chalen.

8. Sa' jun kutank, linmamá kit'ane' chirub'el li iiq', rub'el kape rikin li iiq', kitoqe 'k li roq'.

9. Kixye re li qawa Patrón: "Qawa Patrón, xtoqe'k li woq'." Poj li roq.
1. Te voy a decir: tuve un abuelo que se llamaba Marcelino Xol. En los viejos tiempos, aquí en Cahabón, la hacienda era sobre todo lo que había aqui en Cahabón.

2. La gente, nuestros hermanos, eran perseguidos, obligados a trabajar por nada, no eran pagados. Así, todo el santo día, en los viejos tiempos, empezaban a trabajar a las seis de la mañana hasta las seis de la noche.

3. En los viejos tiempos, había mucho sufrimiento aquí en Cahabón, en Sepacuite, todo Cahabón, todos los lugares, todas las aldeas eran llamados al trabajo.

4. Los niños tenían los 10 años cuando eran mandados al trabajo. Ya que así era la mente del patrón Champney, para que trabajen.

5. Si había una mujer soltera, tenía que casarse porque no era aceptable.

6. Los dias pasaban, y no se les daba ni el machete para trabajar y la gente tenía miedo porque no tenía nada, era pobre.

7. Las pobres esposas se levantaban a las dos de la mañana, tres de la mañana, para juntar las tortillas para los hombres que salian a trabajar. Y así, siempre, siempre.

8. Un día, mi abuelo cayó bajo la carga, bajo la carga de café, y su pierna se rompió.

9. Dijo al patrón "Don, mi pierna está rota”. Su pierna había hinchado. 
10. Pués kixye re naq "tathilanq sa' $l i$ kab'”. Ab'anan naq xhilank sa' li kab', xe'xtaqla chaq li ik'e re tixyiib' li ab'. ¡Ink'a xe'raj naq ta thilanq! ¡Ut li roq', pero más kaq! ¡Li poj! Yo chi yiib'ank, yo chi yiib'ank, yo chi yiib'ank li ik'e sa' ochoch, más li rahilal, nim li roq, ab'an nayiib' li ik'e, xb'aan naq ink'a nayiib' li ik'e, taqlanb'ileb' chi k'anjelak sa' li k'anjel aran sa Xalab'e aran, naq xik aran Las Casas, xb'aan naq kiru li carreteer a'an a pura piocha.

11. Aran neke'taqla, aran xe'xk'ul chaq li rahilal, li wa maaka. Ra... Aran neke 'taqla naq ink'a neke'wulak chi k'anjelak. Wan nab'al xe'kam aran, xe'osok sa' li trabaj... Jo'ka'an naq, ok'e li kutan, kiraho, kiraho li mama'in.

12. 'Ink'a naru naq kama'an yooko chi xkuyb'al, anaqwank, tinsik' ink'a'uxl, chan, tinch'utuneb' li k'aleb'aal, to'ok chi aatinak, to'ok chi na'leb'ak'.

13. “ ¿K'a'ut chi kama’in xe’xb’aanunkil ? ¿K'a'ut junelik, eb’laj asyent junelik yookeb' chi yeb'al, rub'el eb' li xxaab'? Ink'a naru chi kama'in. Laa'o twank qak'ulub' naq tooe'xtoj, naq tooe'xtenq'a. Ink'a naru sa'junelik yooko sa' rahilal, chi q'eq chi kutank, ut maak'a' li qawa, maak'a' li quk'a'.

14. Kixyere: "Anaqwank, nanyere laa'ex chixjunil'ex, naq ink'a neke'xtoj, ink'a chik took'anjelak", x'ok xyeb'alre li kristiaan, x'ok xyeb'alre li kristiaan, x'ok xyeb'alre li kristiaan. Xe'ok chi po'ok rechb'een eb'laj asyent, xe'ok chi po'ok..."
10. Entonces éste le dijo: "Descansarás en casa”, pero mientras descansaba, mandaron maguey para que arreglara hamacas. ¡No querían que descansara! Y su pierna, ;toda roja! ¡Hinchada! Tejía, tejía, tejía el maguey en casa, y sufría, su pierna estaba enorme, pero seguía, sino lo hubieran mandado a trabajar al Cruce de Las Casas, ya que allá hicieron el camino a pura piocha.

11. Mandaban a unos allí, y allí recibían el sufrimiento, no tenían nada de comer. Era muy duro... Alli es donde mandaban a los que no iban a trabajar. Muchos murieron allá, terminaron su vida en el trabajo... Así fue cómo vino el día en que sufrió, sufrió mi abuelo.

12. "No es posible que aguantemos esto. Ahora voy a buscar mi pensamiento, dijo, voy a reunir las aldeas, vamos a hablar, vamos a formar ideas".

13. “PPor qué nos hacen eso? ¿Por qué sólo los propietarios mandan, nos mantienen bajo sus zapatos? Ya no puede durar. Deben pagarnos, ayudarnos. No es posible que siempre estemos en el sufrimiento, día y noche, y que no recibamos nuestra tortilla, nuestra bebida".

14. Les dijo: "Ahora, les digo a todos, mientras no nos paguen, no iremos a trabajar", empezó a decir a la gente, y no dejó de hablarles. Los propietarios empezaron a sentir rabia contra él... 
15. Sa'jun kutank, kixch'utuneb' li kristiaan, utxe'xb'aanujun manifestación arin Chi K'ajb'om, rikin b'andeer chi junil, sa' jolom linmama'. Xe'wulak sa' li ch'ocheb'aal na'ajej jolom, xe'ok chi aatinak, xe'xqaal laj asyent: 'Laa'ex nekexsaho rikin li qawiq'wo. Yookex chi b'ihomo'k laa'ex rikin li qawiq'wo. Laa'ex laj asyent. Anaqwank kiraq'e a'in, anaqwank laa'o tento naq nawank qak'ulub', laa'o li po're, li ra, laa'o li ne'b'a'o. Ink'a naru naq laa'o junelik yooko chi xkuyb'al li rahilal".

16. Li kutank yo chi nume’k. “'K'aru tinb'aanu?"chan li mama'in.

17. Xko'o, toj aran xtaw li kamion, aran Lankin. Xko'o Kob'an, xko xpatz'b'al lix na'leb'. ¿Chan ru naq wi'? Kiaatinak rikin jun aj licenciado, xtaw li licenciado XX kixyere: "Mat k'a'uxlak, laa'in tinsumenq chan ru nab'aanumank”. Kixtaqla li chaq'ra, x'ok xk'uub'ankil li kristiaan, li kristiaan, li kristiaan, toj chi junil li kristiaan.

18. ¡Hi, ut li alcalde! Ma ka'ch'in ki raho, E.F., a'aneb', eb'li ras ritzin, neke'raj xe'xk'ux raj.

19. Ut a'an yo xk'uub'ankil eb' li kristiaan, yo xk'uub'ankil, xyeb'al li na'leb', xyeb'al li na'leb', xyeb'al li na'leb'.

20. Xe'chalk wi chik xsikb'al, xko'o chik sa'tzalam, kielk wi'chik chaq, xko'o wi' chik, elk wi' chaq, xko wi' chik, elk wi'chaq, xko wi'chik, yo, yo!

21. Lix jolom li alcalde, kixpo', kiril naq ink'a chik neke'paab'ank, ka'ch'in más paab'anb'il li mama'in, li kristiaan más neke'xpatz' li mama'in, ink'a chik mas li alcalde.
15. Un día, juntó a toda la gente, hicieron una manifestación aquí en Cahabón, todos con banderolas, y mi abuelo la encabezaba. Fueron al Registro de tierras, empezaron a hablar, a acusar a los propietarios: "Ustedes viven bien poniéndonos de rodilla. Se enriquecen poniéndonos de rodilla. Ustedes los propietarios. Ahora ha terminado. Ahora, hace falta que recibamos lo que se debe, nosotros los pobres, nosotros que sufrimos y estamos sin nada. No se puede que sólo nosotros estemos aguantando en el sufrimiento”.

16. Los días pasaban; “¿qué voy a hacer?” dijo mi abuelo.

17. Se fue hasta el camión de Lanquín. Se fue a Cobán, se fue a pedir ideas. ¿Cómo? Habló con un abogado, encontró al licenciado XX y aquel le dijo: "No tengas pena, te voy a decir cómo hacer”. Mandó las quejas adecuadas. Organizó a la gente, la gente, la gente, hasta toda la gente...

18. ¡Ah, y el alcalde! Sufrió mucho, $X X$ $y$ todos sus hermanos [aliados], lo querían comer.

19. Él organizaba a la gente, organizaba diciendo ideas, diciendo ideas, diciendo ideas...

20. Vinieron a buscarle, se fue a la cárcel, salió, volvió a la cárcel, salió de nuevo, se fue otra vez, no paraba.

21. En su mente, el alcalde se enfadó, vio que no más le obedecían, sino obedecían a mi abuelo, la gente pedía cosas a mi abuelo y no al alcalde. 
22. 'Laa'o, chan, wank li qa k'ulub', komonex, komonex chi junilex, ma ink'a neke'tojok, ¿ani natrab'ajik ? Toj tooe'xtoj, tootrab'ajiq, ¿ma toowank jun li b'atz'um rikin laj asyent?

23. ¡Hi, manifestaciones! Yaal, xe'saho, xe'saho! Yo chi nume'k li chi'ab', xe'ok chi t'ane'k li asyent, kit'ane'li asyent re li Sepacuyte, xe'ok chi elk eb'li asyent.

24. Entonces, mare sa'li sesenta y nueve, entonces xe'ok chi k'uub'ank eb'li militar, eb'li ladino, eb'li asyent, re te'xkamsi li mama'in.

25. Sa' jun li kutank, kixye naq: anaqwank nawaj xyeb'al eere naq, "mat k'a'uxlak, laa'in junelik yookeb' chiwix, re in chapb'al, naab'al te'raj inkamsinkil".

26. ¡Uh! xe'ok li persecucion chirix, naxik Kob'an, nachalk, naxik, nachalk, naxik, nachalk, ut li kristiaan, xe'usaa, xe'ok chi trab'aj li ru li chaab'il.

27. Entonces, sa' junxil wank li reetalil naq wank b'ayaq li aj comuniist, ab'an a'aneb'a'an moko wankeb'.

28. “Anaqwank, moko k'a'uxla chaq, laa'in ink'a nikinxu'wa, ut kristiaanex laa'ex, ilomaq sa' eech'ool, ana'eb'neke'raj link'etb'al, neke 'raj linkamsinkil, pero moko te'ru'.

29. ¿Entonces, chirix a'an, k'aru xb'aanu li mama'in?

30. Sa'jun kutank, yooko chi wark, laa'in wankin wukub' chihab', jun jojyin, kichup li luz sa' li tenamit, wan li mama 'in, kik'ulun chaq li k'aleb'aal. Doce de la noche: "; Abren la puerta por favor! Abren la puerta! Si no la abren, vamos a abrir la puerta" $\mathrm{Li}$ mama'in kixkub'rib'rub'el li ch'aat,
22. "Nosotros, dijo, tenemos derecho, todos ustedes, compañeros, si no pagan, ¿quién va a trabajar? Cuando nos paguen, iremos a trabajar, pero no somos un juguete para los propietarios".

23. ¡Ah, las manifestaciones! De veras, se volvieron contentos y mejoró la situación. Pasaban los años y las haciendas empezaron a caer, cayó Sepacuite, y los grandes propietarios empezaron a salir.

24. Entonces, quizás en el 1969, empezaron los militares, los ladinos, los grandes propietarios a organizarse para matar a mi abuelo...

25. Un dia, dijo: "Ahora, quiero decirles que no tengan pena, sólo me quieren a mí, me quieren agarrar, muchos quieren matarme"

26. ¡Ah! Empezaron la persecución en su contra, él iba a Cobán, regresaba, salia, regresaba, y la gente, su situación mejoraba, empezaron a trabajar bien.

27. Entonces llegó el mensaje que había comunistas. Pero ellos no eran comunistas.

28. "Ahora, no tengan pena, no tengo miedo, y ustedes, miren en sus corazones, me quieren golpear, me quieren matar, pero no podrán."

29. ¿Entonces que hizo mi abuelo?

30. Un día, estábamos durmiendo, tenía yo siete años, una noche la luz se apagó en todo el pueblo. Mi abuelo estaba aquí, había vuelto de una aldea. A medianoche: ";Abran la puerta, abran la puerta! Si no la abren, jvamos a abrir la puerta!” Mi abuelo se puso debajo de la cama. 
30. junpaataq, b'la! Xtolk'e li puerta. Wankeb' soldados, wankeb' a'in li qawa $X$ ut $Y$, waran li puub' ; xinxu'wa laa'in. Xe'xchap. "¿K'aru teeraj laa'ex, chan linwa' re eb', k'aru yookeb'xb'aanunkil?"

31. Jo'ka'an xe'xk'am lin mama', xe'xq'uyukrib' chi ru li pek.

32. “'K'aru yookex? ;Ay dios! Chanre li wixa'an, kiyaab'ak, xko'o li wixa'an chirix lin mama', xyaab' li wixa'an, xe'ok chirix li calvario, xexk'e vuelta chi re li ha', wank b' $i$ ' li escuela, yo..., xooyaab'ak sa' li $k a b^{\prime}(. .$.$) .$

33. Chirix a'an, li wixa'an xye reesil sa'li poopol, kichalk li comision chi rilb'al li puerta. "'Oh! Mira li pasador, jo'ka'an naq xe'xten, jo'ka'an naq xe'ok', xko'eb'.

34. Entonces, xko'o li ab'uelita Kob'an, xye li eesilal... maak'a'.

35. (...).

36. Marcelino kixra li k'aleb'aal, kixtenq'a li k'aleb'aal chi junil, kixra chi anchal ixch'ool, toj te'xk'am.

37. Ut laa'in nanjultika chi anchal linch'ool xb'aan naq jun winq kixb'eeres sa'xtenamit.

38. Li kutank nanume', li kutank nanume' chik, siempre neke'xye li kristiaan sa' li k'aleb'aal, wa'e sa'li qa ch'ool sa' jolom qawa Marcelino. Bantiox re a'an jo' 'ka'an naq anaqwank xoo'usa, bantiox re a'an $x b^{\prime}$ aan a'an yo chi wakliik, xb'aan naq ink'a wanko sa'rub' li asyent anaqwank, a'an tz'aqal li kitenq'a re li na 'leb'a'in.

39. Ink'aneke'xyesa'lixu'wakanaqwank.
30. Muy rápido, ¡blam! se rompió la puerta. Había soldados, había Xe Y, con fusiles; yo estaba atemorizado. Lo agarraron. "¿Qué quieren, les dijo, ¿qué están haciendo?”

31. Asífue cómo se llevaron a mi abuelo. Lo arrastraron en las piedras.

32. “QQué hacen? ¡Dios mío!”, dijo mi abuela, lloraba, se fue detrás de mi abuelo, lloraba mi abuela, pasaron detrás del calvario, dieron la vuelta cerca del río, donde está la escuela, siguieron..., llorábamos en la casa (...).

33. Después, mi abuela se fue a la alcaldía, una comisión llegó para mirar la puerta. "Mira el pasador, asi lo forzaron y así entraron", $y$ se fueron.

34. Entonces la abuela fue a Cobán, contó lo que había pasado... no hicieron nada.

35. (...).

36. Marcelino amaba a las aldeas, les ayudó mucho, les ayudó a todas, les quería con todo su corazón, hasta que lo llevaron.

37. Y me acuerdo en todo mi corazón de un hombre que puso en marcha a su pueblo.

38. Los días pasan, los días pasan y la gente de las aldeas dice todavía que Marcelino está en su corazón y en su mente. Gracias a él, estamos mejor hoy, nos hemos levantado, ya no estamos en manos de la hacienda, sus ideas nos han ayudado mucho.

39. Ya no hablan con miedo ahora.

Recuadro 2 - Una narrativa de la lucha por la tierra:

Martín cuenta la historia de su abuelo Marcelino Xol. Se ha traducido

lo más literalmente posible del q’eqchi al castellano. 


\section{Punto de vista de la narrativa de Martín}

El punto de vista adoptado por Martín en su relato es muy particular: no intenta borrar al narrador, por lo contrario siempre recurre a la personalización de su palabra, estando en una situación de conversación: "te voy a decir" (secuencia 1, recuadro 2), "mi abuelo" (secuencias 1, 8, 15, 16, 21, 29-32), "me acuerdo con todo mi corazón" (secuencia 37), subrayando su vínculo personal con el personaje de la historia. Sin embargo, Martín no describe cómo se enteró de esta historia (se puede hacer la hipótesis de que Martín era muy pequeño cuando su abuelo, el protagonista de la historia, murió, y que sólo conoce esta historia porque su familia se la ha contado). La cuenta como si fuera una historia establecida, objetiva, con saber casi ilimitado. Así, Martín empieza y termina con reflexiones históricas y filosóficas (secuencias 2-7), expresa el punto de vista de su abuelo Marcelino a través de sus ideas y de sus acciones progresivas, y también transcribe las reacciones y los sentimientos de los propietarios de las fincas (los enemigos de Marcelino), acusados de explotar a los colonos (secuencias 14 y 18).

El relato empieza con la expresión propia de las "palabras sagradas" relativa a los tiempos antiguos y sigue con la expresión del sufrimiento típico del género de "lo padecido": "Sa junxil chaq kutank, más chaq li rahilal a'in chi $K$ 'ajb'om - En los viejos tiempos, había mucho sufrimiento aquí en Cahabón" (secuencia 3). Sin embargo, no se conforma con lo sufrido: expone una reacción de lucha contra la sujeción. Entre las reflexiones de Marcelino que reporta la narración, se puede destacar, por ejemplo: "No se puede que sólo nosotros estemos aguantando en el sufrimiento" (secuencia 15).

Martín usa desde la primera frase el modulador verbal completivo lejano $k$ (se repite en las secuencias 8,9 y siguientes), que se emplea a menudo en las palabras míticas para aludir a un tiempo remoto y a actos fundadores, distintos del régimen histórico normal, como en los ejemplos siguientes: "Qawa Dios, ak kixk'e chaq li ixim cho'q qe toj maak'a' nayo'la-Dios nos dio el maíz, cuando no había nacido nada todavía" (Angelina, anciana de Cahabón); "Sa' jun chaab 'il rochoch pek, aran kiwan qamama' Qawa' Tzuultaq'a-En una cueva bonita, allí habitaba nuestro antiguo Señor Tzuultaq 'a" (El Sol y la Luna, Estrada Monroy 1990, p. 108). Ahora bien, en el relato de Martín observamos la misma riqueza de moduladores que en el relato del Sol y de la Luna ${ }^{15}$. Su narración transforma en actos míticos hechos que le fueron contados por sus padres, a la vez que el abuelo se vuelve un héroe similar al del género de "las historias".

15. Kockelman (2007, p. 320) reveló la riqueza de los tiempos verbales usados en el relato del Sol y de la Luna, en el que se usan tanto el $n a(k)$ - (presente habitual, pero también de verdad para siempre), como el $x$ - (tiempo pasado, aspecto perfecto), como el $k$ - (tiempo pasado lejano, aspecto perfecto). 
Así pues Martín hace de su abuelo el personaje principal de la lucha campesina (secuencia 14), un héroe capaz de morir y renacer, para que los hombres puedan dar sentido a su propio tiempo. Con su relato, intenta participar, más allá de su contribución al trabajo de una etnógrafa, a la formación de una "leyenda" alrededor de Marcelino Xol, aunque no todos compartan su versión. En efecto, según otros ancianos q'eqchi'es, Marcelino no fue un héroe: " $\mathrm{Li}$ qawachin a'an, yo chi qa ch 'ikb 'al sa' ch'aajkilal. Moko us ta nokoelk. Aran xe'ok chi pleetik rikin li mama' a'an-Este señor nos metió en problemas. No salimos bien. Empezaron a pelear con ese señor", explica Isidro, un anciano de Tzalamtún.

Lo cual permite subrayar que el relato de Martín -hombre de ciudad, bastante joven, y que, por su estatuto, difiere de los ancianos que controlan en general las "historias" - no es una narrativa consensual, y construye una versión peculiar que ha de ponerse en perspectiva. En la sección siguiente, analizaremos los elementos narrativos del relato de Martín que atestiguan la continuidad o el cambio con respecto a los géneros de las "historias" y de "lo padecido".

\section{Trama narrativa del relato de Martín}

Se resume la intriga del relato de Martín en el recuadro 3.

1. El territorio de la "Asyent": una situación de sujeción.

2. El evento desencadenante: la caída de Marcelino bajo la carga de café, la herida, obligación de seguir trabajando e imposibilidad de huir.

3. Cambio de ideas, calificación de injusticia. Concertación colectiva en las aldeas de colonos. Rabia de los propietarios.

4. Salida hacia la ciudad de Cobán para buscar ayuda de un abogado.

5. Organización de las aldeas.

6. Reacción de los propietarios (puesta en la cárcel).

7. Los colonos se niegan a ir al trabajo y manifiestan.

8. Caída de las haciendas.

9. Organización de los ladinos para matar a Marcelino Xol.

10. Les acusan de ser comunistas.

11. Anuncio de Marcelino: "me quieren matar".

12. Asesinato.

13. Impunidad.

14. Conclusión: "Gracias a él, nos hemos levantado".

Recuadro 3 - Resumen del relato de Martín. 
El territorio bajo sujeción (situación inicial): el ciclo de invasiones

Martín empieza su relato como las palabras sagradas, partiendo de un territorio establecido: el de la Hacienda. Sin embargo, este territorio no pertenece a un Señor quien respete las normas de reciprocidad. Inmediatamente, pone de realce la situación de sujeción (secuencias 1 y 2). Esto encaja con la versión de varios otros q'eqchi'es quienes, a propósito de "lo padecido", presentan la "invasión" de los "aj asyent" (hacenderos) como un nuevo golpe en una serie histórica de intrusiones sufridas en un territorio, con una profundidad temporal larga. 'Li asyent kiramok li qana' qayu'wa, a'an kinumta li asyent saqab'een -La Hacienda ató a nuestros padres y madres, la Hacienda tomó el poder sobre nosotros", dice Isidro, anciano de Tzalamtun. Lisandro, de Chiacach, plantea la Conquista y la Hacienda como etapas equivalentes del ciclo de invasiones: "El señor Champney mandaba a todos a trabajar en su finca, como era conquistador Benjamín Champney".

\section{El evento desencadenador y la denuncia de la injusticia inicial}

Mientras en la palabra sagrada "el sol y la luna", el hito que acarrea la acción dramática es un robo (transgresión de la regla de reciprocidad con el Tzuultaq'a), en la historia de Marcelino Xol, el evento desencadenador es la caída bajo la carga de café (Martín, secuencia 8). Este acontecimiento pone de relieve los abusos y la injusticia del colonato: el personaje toma conciencia y decide reaccionar.

Revela la ausencia de reconocimiento del propietario legal hacia sus trabajadores. Marcelino Xol denuncia la situación inicial como injusta: el trabajo en la Hacienda equivale a un robo, ya que no recibe su debido pago (secuencia 13). El relato muestra, en un primer tiempo, que no existen sanciones en contra del dueño ilegítimo, sino que al contrario, la sanción puede afectar a las víctimas que quieran huir (secuencias 10 y 11). Esta inversión de valores (el sistema de dominación de la Hacienda) es similar a la que se encuentra en los cuentos sobre los Aj Q'eq.

Para ser legítimo, un dueño tiene que respetar a sus sujetos no solo pagándoles (secuencia 2) sino también dándoles de comer ("no es posible [...] que no recibamos nuestra tortilla, nuestra bebida", secuencia 13, expresión que se usa en general en las rogaciones hacia el Tzuultaq'a).

El relato de Martín introduce de hecho una nueva diferencia en la dinámica narrativa: no se trata de una intrusión ni de un robo transgresivo que afectarían al Señor, sino de un Señor injusto contra el cual es legítimo rebelarse.

La salida y la ayuda del abogado

Marcelino emprende una lucha jurídica para obtener un sueldo buscando ayuda en otro territorio. Este motivo se encuentra en la categoría de "las 
historias", pero Martín no precisa qué tipo de reciprocidad se instaura con aquel espacio. En efecto, Cobán no representa aquí el predio de un Tzuultaq 'a, sino que procura el acceso a la ley y la política nacionales. Cabe notar que Martín no menciona si Marcelino Xol se comprometió en un partido político ${ }^{16}$ : reduce a lo mínimo la dimensión nacional del conflicto. La salida y la búsqueda de ayuda externa operan en la narrativa como causa de la ruptura del cara a cara local. El abogado del relato de Martín aparece como un equivalente del "prestador de disfraz" de las "historias sagradas". Prestando su conocimiento del lenguaje jurídico (Martín, secuencia 17), formaliza los sufrimientos de los q'eqchi'es en una cuestión de derecho laboral capaz de disturbar a los propietarios locales.

\section{La organización colectiva}

Otro motivo del relato de Martín ofrece gran similitud con las tramas míticas. Se trata de la secuencia de la concertación con las aldeas: "Voy a buscar mi pensamiento, dijo, voy a reunir las aldeas, vamos a hablar y vamos a formar ideas" (Martín, secuencia 12). En "las historias", los ancianos o las Montañas-Valles también se juntan para "mezclar" sus ideas y decidir el mejor camino (Burkitt 1917-1920; Cruz Torres 1978, p. 87-97). Dichas acciones son esenciales puesto que conllevan a la creación, o más bien al cambio de valores dentro de las aldeas. Es menester convencer, levantar (wakliik) las conciencias, demostrar que el intercambio con la hacienda no es equitativo (Martín, secuencia 13). Se construye una argumentación en contra de los grandes propietarios, acusándoles de enriquecerse gracias a los sufrimientos y la sujeción de los colonos (Martín, secuencia 15). De manera similar a lo que ocurre en el relato de "la hija de Xukaneb", el relato sobre Marcelino pone en escena un enfrentamiento con diferentes protagonistas, con estrategias y armas para vencer al enemigo. Aquí el enfrentamiento se realiza bajo la forma de procesos legales y manifestaciones.

\section{La transgresión y la rabia}

Surge la rabia de los grandes propietarios frente a los que se atreven a desafiarles y a transgredir las reglas de la finca (Martín, secuencia 14). La rabia (josq ’il) es un rasgo de carácter sistemáticos de las Montañas-Valles, frente a cualquier infracción en sus territorios o en caso de robo de sus bienes (su rabia se expresa a menudo por el trueno). Por ejemplo, en el cuento "El robo de la hija de Xukaneb", se menciona: “Numtajenaq xjosq'il Xukaneb xb'aan xsachik li $x r a b$ 'in... -Xukaneb, lleno de rabia porque había perdido a su hija..." (Ak' kutan 1999, p. 28-34). 


\section{El sacrificio}

Existe otro punto de similitud entre el relato de Martín y una "palabra sagrada": el tema del sacrificio. Marcelino se sacrifica sabiendo que su acción ya cambió el mundo, será exitosa e introdujo una revolución en la mente de "las personas": la de combatir por su dignidad (secuencias 28, 38 y 39). "Las historias" constan también de una sucesión de sacrificios. Por ejemplo, en la narrativa del Sol y de la Luna, la Luna se sabe sacrificada por la transgresión que perpetró al huir de la casa de su padre: “Anaqwank, xoo oso'-Ahora, hemos muerto" (Estrada Monroy 1990).

Hay que notar que, en ambos casos, sólo matan a los héroes o a una víctima sacrificial. Martín escoge relatar únicamente el martirio de su abuelo sin mencionar la política de terror que infligían a toda la población. En efecto, tanto los historiadores como la población local confirman que masacres afectaron a familias y aldeas enteras en Cahabón: mujeres sufrieron violaciones, hombres fueron torturados, centenas de cuerpos desaparecieron en el río. Muchas casas fueron quemadas y familias enteras tuvieron que huir a la selva durante semanas o incluso años (Grandin 2004, Huet 2006).

Muchos de los q'eqchi'es con quienes hablamos consideran estos sacrificios como algo inevitable, ya que los colonos tuvieron una posición colectiva de oposición a la Hacienda y que toda transgresión o rebelión, aun justificada, provoca castigos. El tema del paso por la muerte se usa mucho en narrativas colectadas en los pueblos. Como la Luna en la historia sagrada que estudiamos antes, varias mujeres usan la expresión: “xinoso' - estuve muerta, terminada, agotada", cuando evocan episodios de la guerra.

Ciertas narrativas sobre la guerra terminan con la obligación de comprar las tierras, siguiendo un trámite administrado por el Instituto Nacional de Transformación Agraria (INTA). Las aldeas organizan, de manera colectiva y solidaria, el pago de las parcelas de cada familia: puede considerarse como un pago tanto financiero como político y simbólico a las autoridades, ya que permite terminar con la represión estatal, y validar un nuevo estatuto de comunidades de pequeños propietarios, así como pasa en las últimas secuencias de la "palabra sagrada" del Sol y de la Luna.

Sin embargo, a pesar de esta nueva situación, es muy difícil "renacer" como pasa en las "palabras sagradas". Así un q'eqchi' dice: "Laa'o li xorahob'tesiik chaq malaj li xqahoy chaq nab'al qa kik'el, maji'nawulaak li tuqtuukil usilal qik'in, maji' -Nosotros que hemos sufrido o que hemos derramado mucha sangre, la paz no ha venido todavía para nosotros" (Huet 2006, p. 216). Otros subrayan el vacío y la impotencia que sienten todavía: "Ra wanko, maak'a tooruuq xb 'aanunkil, [...] xb 'aan naq rahob'tesinb 'ilo chaq, [...] más okenaq li xsujew, chan chan jun awimq: pero wi' natoqe' b'ayaq, moko sa ta chik 
xch'ool naq naki, moko sa ta chikxch'ool naq nauuchink, kama'ano chik laa'o yooko xk'ulb'al. -Estamos tristes, no podemos hacer nada, [...] porque estamos en la tristeza y el dolor, el mal ha entrado profundamente, como pasa con una planta: si está un poco quebrada, ya no puede crecer, ya no puede dar frutos, esto es lo que nos está pasando" (José, anciano de Chiakach).

Como lo notamos a continuación en el tabla 1, el relato de Martín introduce también una diferencia con las narrativas de "lo padecido" durante el "gran sufrimiento" (li nim rahilal), ya que pone de relieve que la lucha encabezada por Marcelino Xol y el conflicto subsiguiente introdujeron una dimensión de ruptura en el tiempo cíclico de violencia sufrida.

Un relato intermediario entre los géneros de "las historias" y de "lo padecido"

El relato sobre Marcelino Xol, analizado a la luz del género de "las historias" y del género de "lo padecido", ofrece similitudes y circulaciones de elementos formales y secuenciales propios de dichos géneros (sufrimiento, héroes, intrusiones, transgresión, rabia y venganzas de dueños, sacrificios, y renacimientos). El relato de Martín quizás podría volverse una "historia" para las generaciones del futuro, haciendo de un líder campesino del siglo XX un héroe del pueblo q'eqchi', conforme con la hipótesis de que los esquemas narrativos de "las historias" contribuyen a la construcción de los relatos de la guerra, ayudando a "pensar" el cambio histórico. Para lograrlo, da una inflexión a la dinámica narrativa: el ciclo de intrusiones y transgresiones pasa a ser un ciclo de resistancias y rebeliones. Al contrario de "las historias", el relato de Martín introduce moralización y juzgamientos relativos a la ética y la justicia. Es un híbrido entre la anécdota personal, el puro relato de "lo padecido" y el relato canónico de una aventura mítica (ver Tabla 1, página siguiente).

\section{Memorias del conflicto}

Si comparamos ahora la narrativa de Martín con narrativas ladinas del conflicto, encontraremos que su relación con el pasado reciente es radicalmente distinta. Lo mostraremos a partir de la historia contada por el ladino Amílcar (Bergeret 2012, p. 675-690), administrador e hijo de un administrador de la finca Champney, el mayor propietario de la zona hasta los años 1950. No podemos en el marco de este artículo caracterizar el estatuto social de esta narrativa entre los ladinos. Sin embargo, se puede hacer la hipótesis de que la presencia de la etnógrafa extranjera es una de las situaciones privilegiadas para expresar estas historias, ya que fue a solicitud de Amílcar que registramos su narrativa. 


\begin{tabular}{|c|c|c|c|}
\hline & Las "historias" & $\begin{array}{c}\text { La lucha contra } \\
\text { "li Asyent" por Martín }\end{array}$ & "Lo padecido" \\
\hline $\begin{array}{c}\text { Estatuto } \\
\text { social }\end{array}$ & $\begin{array}{c}\text { Situaciones } \\
\text { de buen ambiente, } \\
\text { en colectividad, } \\
\text { en la noche o en velas } \\
\text { rituales. } \\
\text { Educación de los } \\
\text { niños, actualizar la } \\
\text { unidad de la comunidad } \\
\text { y su arraigamiento } \\
\text { en un territorio, rituales, } \\
\text { conversación con } \\
\text { extranjeros. }\end{array}$ & $\begin{array}{c}\text { Narrativa a la } \\
\text { etnógrafa extranjera; } \\
\text { conversación } \\
\text { inter-individual. } \\
\text { Objetivo de dar } \\
\text { testimonio de la vida } \\
\text { heróica del abuelo. } \\
\text { Género no estabilizado } \\
\text { dentro } \\
\text { de las aldeas. }\end{array}$ & $\begin{array}{c}\text { Relatos } \\
\text { inter-individuales } \\
\text { Ambiente de tristeza, } \\
\text { sufrimiento y pesar. } \\
\text { Relatos sobre } \\
\text { la guerra: situaciones } \\
\text { íntimas, género no } \\
\text { estabilizado dentro } \\
\text { de las aldeas. }\end{array}$ \\
\hline $\begin{array}{c}\text { Punto } \\
\text { de vista } \\
\text { del } \\
\text { narrador }{ }^{17}\end{array}$ & $\begin{array}{c}\text { Externo. } \\
\text { Objetividad. } \\
\text { Los hechos son } \\
\text { realidades que no } \\
\text { necesitan justificación } \\
\text { ni explicación. } \\
\text { Saber ilimitado } \\
\text { y neutral (se reportan } \\
\text { las acciones y los } \\
\text { sentimientos de } \\
\text { todos los personajes; } \\
\text { no se aprecia ninguna } \\
\text { implicación del } \\
\text { narrador para calificar } \\
\text { a los grupos como } \\
\text { buenos o malos). }\end{array}$ & $\begin{array}{c}\text { Interno. } \\
\text { Intención de } \\
\text { construir una historia } \\
\text { establecida objetiva. } \\
\text { No explica quién } \\
\text { le contó la historia. } \\
\text { Saber extenso } \\
\text { y militante (expone los } \\
\text { sentimientos } \\
\text { de diferentes grupos, } \\
\text { pero el relato } \\
\text { privilegia un grupo } \\
\text { "bueno" que enfrenta } \\
\text { injusticias). }\end{array}$ & $\begin{array}{c}\text { Interno. } \\
\text { Subjetividad. } \\
\text { A menudo: } \\
\text { autobiografía o } \\
\text { intento de reproducir } \\
\text { el punto de vista del } \\
\text { personaje principal, es } \\
\text { decir de la víctima. } \\
\text { Saber limitado: } \\
\text { incertidumbre } \\
\text { y sombras en cuanto a } \\
\text { varios elementos } \\
\text { de la historia. }\end{array}$ \\
\hline $\begin{array}{c}\text { Tema y } \\
\text { personajes }\end{array}$ & $\begin{array}{l}\text { Intrusión en territorios, } \\
\text { raptos de prometidas, } \\
\text { etc. } \\
\text { Multiplicidad de } \\
\text { personajes: Tzuultaq'a, } \\
\text { Chol Winq, animales, } \\
\text { etc. }\end{array}$ & $\begin{array}{l}\text { Lucha histórica entre } \\
\text { grupos sociales: } \\
\text { Eb'li kristiaan } \\
\text { (la gente), eb'li } \\
\text { qas qitzin (nuestros } \\
\text { hermanos), } \\
\text { el'li k'aleb'aal } \\
\text { (las aldeas), } \\
\text { laa'o li ne'b'a'o } \\
\text { (nosotros los pobres) / }\end{array}$ & $\begin{array}{l}\text { Individuo sufriendo un } \\
\text { accidente, un conflicto, } \\
\text { una persecución. } \\
\text { Laa'in (yo), } \\
\text { laa'o (nosotros), } \\
\text { inyuwa (mi padre), } \\
\text { eb'li qas qitizin } \\
\text { (mis hermanos) } \\
\text { / }\end{array}$ \\
\hline
\end{tabular}

17. Nos inspiramos aquí del método propuesto por Rabatel (1997) que distingue dentro del punto de vista del narrador, la focalización interna o externa, el saber, y la intención de objetividad o de subjetividad. 


\begin{tabular}{|c|c|c|c|}
\hline $\begin{array}{c}\text { Tema y } \\
\text { personajes }\end{array}$ & & $\begin{array}{c}\text { Champney, } \\
\text { li patrón, laj asyent } \\
\text { (los propietarios de } \\
\text { Hacienda), li alcalde, } \\
\text { eb'li ladino, } \\
\text { eb'li militar. }\end{array}$ & $\begin{array}{c}\text { li Auto Defensa, } \\
\text { aj Patruuyeb' } \\
\text { (las patrullas de } \\
\text { autodefensa civil), eb' } \\
\text { li militar, li oficial, li } \\
\text { comisionado }^{18}\end{array}$ \\
\hline Tiempos & $\begin{array}{c}\text { El principio del mundo, } \\
\text { los antepasados xe ton. } \\
\text { Tiempo cíclico } \\
\text { con transgresiones } \\
\text { estableciendo } \\
\text { las reglas } \\
\text { Momento a-histórico } \\
\text { Momento históricoque } \\
\text { se ha vuelto una } \\
\text { "historia" }\end{array}$ & $\begin{array}{c}\text { Época de li Asyent } \\
\text { (la Hacienda) } \\
\text { (sin indicaciones } \\
\text { cronológicas precisas } \\
\text {-una sola mención, } \\
\text { 1969) } \\
\text { Nueva etapa en un } \\
\text { ciclo de intrusiones } \\
\text { injustas y las } \\
\text { resistancias/rebeldías } \\
\text { en contra de éstas. }\end{array}$ & $\begin{array}{l}\text { Momento cercano } \\
\text { o época de } l i \text { Nim } \\
\text { Rahilal vivida o } \\
\text { relatada por la familia, } \\
\text { vivida como una } \\
\text { ruptura. }\end{array}$ \\
\hline Intriga & $\begin{array}{c}\text { Variaciones alrededor } \\
\text { de la dinámica } \\
\text { Territorio establecido } \\
\rightarrow \text { Intrusión } \\
\rightarrow \text { Robo-transgresión- } \\
\text { evento desencadenador } \\
\rightarrow \text { Sanción-sacrificio } \\
\rightarrow \ldots\end{array}$ & $\begin{array}{l}\text { Territorio dominado } \\
\text { por intrusos } \\
\rightarrow \text { accidente } \\
\text { desencadenador } \\
\rightarrow \text { denuncia de } \\
\text { la injusticia en el } \\
\text { funcionamiento del } \\
\text { territorio por el héroe } \\
\rightarrow \text { lucha } \\
\rightarrow \text { sanción-sacrificio }\end{array}$ & $\begin{array}{l}\text { Una acción central } \\
\text { Un accidente } \\
\text { o un conflicto }\end{array}$ \\
\hline
\end{tabular}

Tabla 1 - Situación del relato de Martín entre los géneros narrativos q’eqchi’es.

Las versiones de Martín y del ladino Amílcar revelan las memorias vivas del conflicto. Proponemos una visualización de éstas (ver Figura 1, páginas siguientes), situándolas con respecto a los principales actos de los regímenes gubernamentales sucesivos. El período oligárquico liberal y de colonización por parte de los alemanes en Alta Verapaz corre entre 1870 y 1944. La primavera democrática se sitúa entre 1944 y 1954, con nuevas leyes estableciendo una moneda única, un código de trabajo, una reforma agraria. El golpe de estado de 1954 termina con la democracia y la reforma agraria. El contexto de la Guerra Fría se caracteriza por la radicalización progresiva del régimen de dictadura controlado por el ejército y por los diferentes movimientos de guerrillas de los

18. Elementos de las narrativas sobre el conflicto citadas en Bergeret (2012, p. 343-351). 
años 1960 y 1970; el periodo de máxima violencia se sitúa entre 1978 y 1982. Siguen la transición de los años 1980 y los Acuerdos de Paz de 1996.

\section{Trama narrativa de la saga familiar ladina}

Resumimos en el recuadro 4 la entrevista con Amílcar.

1. “Tengo 62 años. Yo nací en el 43, pero como nací en la finca, conocí lo que mucho antes ha sido $[\ldots]$ ".

2. "Mi papá era agricultor, y era [...] segundo administrador de la finca...". Descripción de la vida del padre.

3. "El historial me lo contaba [...] yo era muy preguntón de patojo, a mí me encanta lo que es la historia."

4. "Quiero contarle que, al inicio, los meros dueños, o sea los que empezaron a comprar las tierras [...]". Principio de la historia: compra de la tierra.

5. "Dice la historia que cuando llegaron, fue cuando los alemanes.... Sabe usted que vinieron los alemanes a comprar toda Alta Verapaz y se vinieron a mezclar con los indígenas."

6. Intento de crear una fábrica de aguardiente.

7. Explicación del fracaso por las creencias y el miedo de los q'eqchi'es (pregunta sobre los "negritos"; explicación).

8. Caracterización de los propietarios: dos primos, Kensett y Walter Champney -uno enfermo, uno fuerte.

9. El pacto entre ellos.

10. La muerte de Walter, indivisión de la tierra para Kensett.

11. Descripción de la finca: casas, muebles, objetos. Descripción del propietario: "yo recuerdo por allá lejos haberlo visto, era un hombre muy alto con una gran barba blanca".

12. La muerte de Kensett. Amílcar empieza esta secuencia del relato con la expresión "dicen que". Transmisión de los bienes a un solo hijo de Walter, Benjamín (pregunta sobre la transmisión a un solo hijo; respuesta).

13. Descripción de la finca: compras de tierras a la gente, crecimiento económico, organización, actividades, el personal, su tratamiento, su pago, extensión de la finca (enumeración de las aldeas que le pertenecían).

14. Benjamín tiene tres hijos naturales.

15. La muerte de Benjamín: el accidente de avión.

16. Pelea de los hijos naturales de Benjamín.

17. Irrupción del narrador con el recuerdo de la entrada al servicio de la finca, descripción breve de las razones de esta opción y de su situación en la época.

18. Descripción de la finca: caminos, transportes. 
Narrativas del conflicto y construcciones del pasado entre los q'eqchi'es

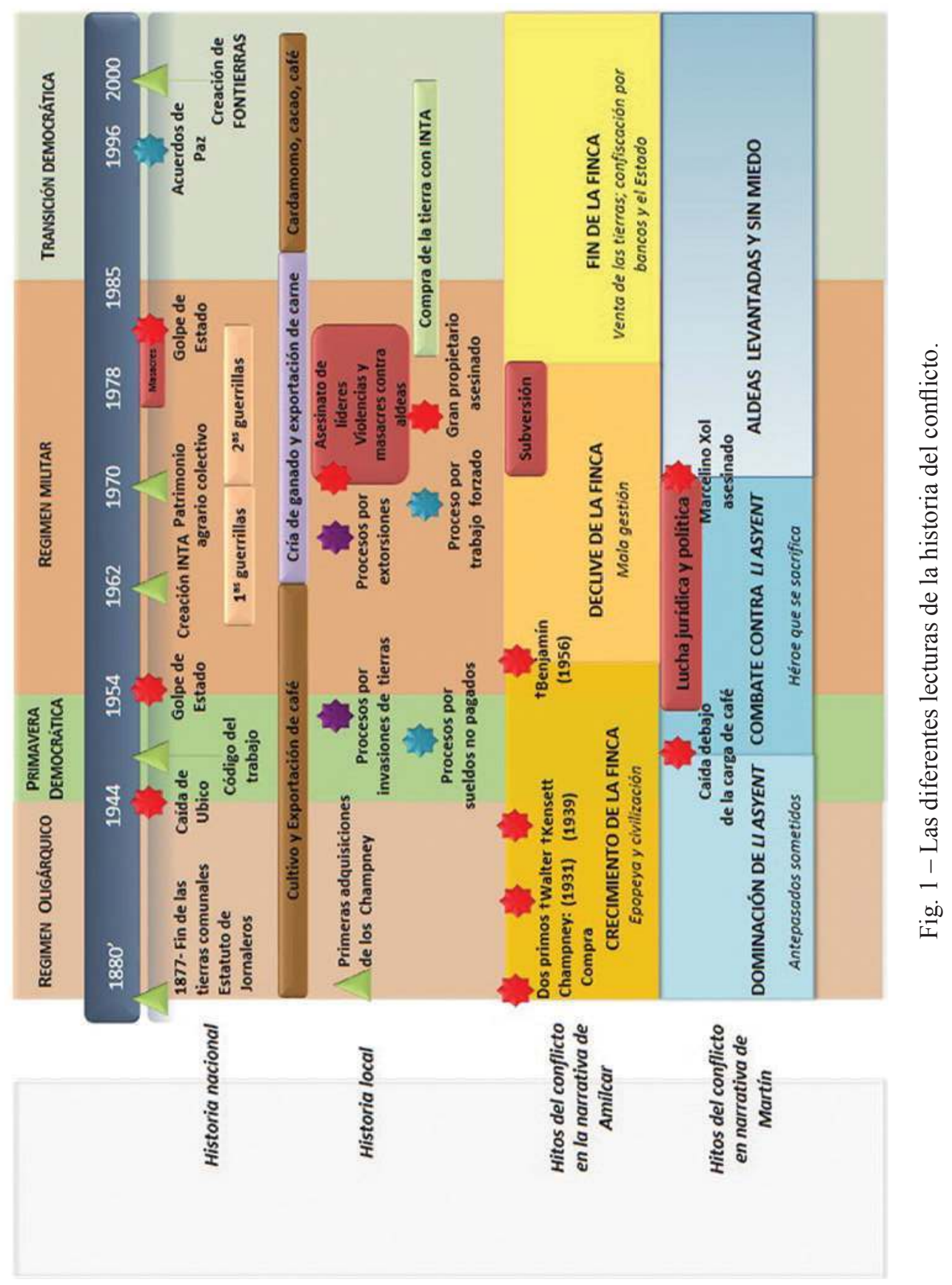


19. Pregunta sobre el trabajo de mayordomo. Descripción de la organización de la finca: categorías de trabajadores, sueldos, trabajo por tarea, y los malos tratamientos respaldados por las autoridades, con referencias a sus propias experiencias. Preguntas sobre detalles. Termina la descripción del trabajo por tarea y concluye "O sea que, en ese tiempo, la gente estaba muy marginada. O sea, la gente estaba muy, vale la palabra, pisoteada, bajo el tacón del pudiente".

20. Organización de fiestas por el finquero.

21. Pregunta sobre las mujeres. Explicación sobre el estatuto de las mujeres.

22. "Cuando derrocaron a Arbenz, había escasez..." Anécdota sobre el suministro en maíz por Benjamín.

23. Pregunta sobre la existencia de monedas de fincas. Contesta con la historia del uso de la moneda-cacao a principio del siglo xx.

24. Pregunta sobre la posición del dueño de la finca respecto al cacao. Contesta evocando las siembras que autorizaba e incentivaba el dueño en las parcelas de los colonos.

25. Pregunta sobre la existencia de una relación entre el dueño y las cofradías. Explicación acerca del control de las fiestas por las autoridades municipales; los comerciantes ladinos; los avances (préstamos reembolsados con el trabajo en la finca) por parte del dueño.

26. Crisis de la finca: los hijos empezaron a vender.

27. "Ya la gente ya dejó de trabajar, cuando la subversión invadió. Empezó a decir a la gente: “¿por qué tienen que trabajar si no les pagan?”Y se fue temiendo la gente, se fue temiendo la gente, ya no llegaron a trabajar. Y en una parte tenían razón porque no les pagaban." - ¿En qué año fue eso? "Eso ya más o menos, fue..., vamos a ver, cuando yo salí de la finca, en el 74 por allí... En el 75 para la 80 se dio todo eso, de que ya... ya estábamos involucrados en la guer... Aquí [por causa de] la subversión, [...] toda la gente se quedó, ya no quería trabajar. Y entonces, cuando eso pasó, el Estado confiscó las tierras, las tierras ociosas las agarró, y pronto las comunidades empezaron a brincar, a pedir las tierras."

28. Venta de la tierra por el hijo Champney: despiden al padre de Amílcar.

Recuadro 4 - Resumen de la narrativa de Amílcar (se señalan las preguntas de la etnógrafa en cursiva), abril 2005.

\section{Comparación entre las narrativas ladina y q'eqchi'}

Esta sección busca contextualizar y poner en perspectiva los hitos temporales de Martín y Amílcar (Figura 1, los dos últimos frisos), con puntos de referencia de ámbito nacional y local (Figura 1, los dos primeros frisos). Se pudo esclarecer y reconstituir las fases del proceso conflictivo local gracias a un trabajo en archivo (AGCA, 1949 y 1951 entre otros) y a la investigación de Grandin (2004). No sólo pondremos de relieve las convergencias, diferencias 
y ocultaciones de las dos narrativas en cuanto a la historia nacional y local, sino también intentaremos entender la experiencia específica del tiempo que propone cada una de ella.

\section{Punto de vista}

El punto de vista de Amílcar es muy diferente del de Martín, puesto que indica mucho más las fuentes de las informaciones que revela y recorre a fechas precisas ("1943", secuencia 1 por ejemplo). Explica cómo conoce los detalles de la historia de la Hacienda: "me lo contaba [mi papá], yo era muy preguntón" (secuencia 3). A lo largo de su relato, sigue haciendo referencias a la vida de su padre o su propia situación en la finca (secuencias 17, 19, 27, 28), lo que da preciosas indicaciones al historiador. Su relato está puntualizado por descripciones abundantes relativas a diferentes aspectos de la finca, a menudo en el marco de respuestas a nuestras preguntas.

Sin embargo, el discurso de Amílcar también integra elementos de construcción de un relato ya establecido y reconocido colectivamente, lo que explicita con el uso de expresiones tales como: "el historial" (secuencia 3), "dice la historia" (secuencia 5), y en varias otras secuencias: "dicen que". Además, el narrador indica que la construcción de la finca de los Champney ocurrió cuando los alemanes se asentaron en la región, lo cual corresponde a un episodio histórico bien estudiado (Wagner 1996). Su narrativa elabora una saga familiar, cuyos miembros no son descritos como héroes, sino como una sucesión generacional (Figura 1) de empresarios más o menos hábiles. Se nota en un primer tiempo el deseo de describir una obra civilizadora, una "edad de oro", con la grandeza de la propiedad, la modernidad del sistema de producción y el refinamiento de las casas de la finca, que por último se matiza con una descripción muy concreta de los medios de sujeción de los trabajadores.

\section{La compra}

El hito temporal inicial de Amílcar es "la compra de las tierras" por los primos Champney - dichas tierras se denominan latifundio (Cambranes 1996) o Hacienda (Wolf and Mintz 1975) en los libros de historia, mientras que los ladinos las llaman Finca, y los q'eqchi'es li asyent. A partir de este "principio de la historia", se crean los antagonismos en cuanto a la legitimidad de los derechos sobre la tierra, los propietarios locales apoyándose en el acto de compra y la Escritura legal, mientras los q'eqchi'es califican este episodio de invasión. Ahora bien, cabe recordar que esta compra radica en la anulación por la República liberal, en 1877, del estatuto colonial de tierras comunales de los pueblos indígenas: esto favoreció la adquisición a precio administrativo muy bajo de estos territorios, e impulsó una inmigración de alemanes, ingleses o estadounidenses, con el objetivo de desarrollar una agricultura exportadora moderna (Figura 1). 


\section{Sistema de dominación de la finca}

Cabe ahora comparar las descripciones que hacen Martín y Amílcar del sistema de dominación instaurado por la Hacienda. El "colonato" designa entre los historiadores un tipo de trabajo forzado en la plantación de café al que sometían a la población indígena que vivía en las tierras del gran propietario, legalizado en Guatemala por el Reglamento de Jornaleros de 1877. Algunos ladinos lo presentan como un intercambio equitativo: una gran propiedad privada deja que familias de colonos vivan en sus tierras, a cambio de su trabajo en las plantaciones de café. Sin embargo, tanto en el relato de Amílcar como en el de Martín, se subrayan los mecanismos de explotación y de control social. Martín subraya primero la obligación (secuencia 2), el trabajo de los niños (secuencia 4), la sujeción de las mujeres (secuencia 5), la ausencia de herramientas (secuencia 6), la ausencia de alimento (secuencia 7), y sigue con los maltratos, la amenaza de ser mandado a los trabajos de carreteras por las autoridades (secuencia 8-10) y la ausencia de pago (secuencia 13). Otros q'eqchi'es explicaron también la interdicción de cultivar productos comerciales y rituales. En cambio, el relato de Amílcar expresa primero cierta admiración por la organización del trabajo. Empieza con las diferentes categorías de trabajadores, explica el trabajo por tarea y el apoyo de las autoridades (secuencia 19). Explica cómo el propietario logra adhesión y respeto organizando fiestas (secuencia 20). Precisa el estatuto de la mujer sólo cuando se le pide detalles (secuencia 21). Detalla la forma en que el patrón incita a los colonos para que cultiven productos para su autosuficiencia (secuencia 24). Por fin, describe los avances y la venta de alcohol en las fiestas ${ }^{19}$ que favorecen la dependencia de los q'eqchi'es a la finca (secuencia 25).

Sin embargo, ambas versiones presentan dos conclusiones muy similares: "Nos mantienen debajo de sus zapatos" explica Martín (secuencia 13); "la gente estaba muy, vale la palabra, pisoteada, bajo el tacón del pudiente" (Amílcar, secuencia 19). Estas dos versiones son ejemplares de la complementariedad de los testimonios, y de la jerarquización de los datos según la perspectiva que cada uno adopta.

\section{Crisis de la finca}

Según Amílcar, la crisis empieza con la desaparición súbita de Champney, en un misterioso accidente de avión, en 1956. En ese momento, se reconfigura la distribución de la tierra en Cahabón, por los conflictos entre los herederos y por

19. La venta de alcohol en las fiestas q'eqchi'es vinculaba en un mismo círculo de dependencia la cofradía q'eqchi' que necesitaba dinero para su santo y su misa, el alcalde que autorizaba la fiesta, los comerciantes ladinos que tenían el monopolio de la venta a la cofradía, y el propietario que daba avances a los trabajadores q'eqchi'es para que puedan pagar el alcohol a la cofradía y cumplir con el ritual, y asegurándose asi su mano de obra. 
su mala gestión (secuencias 16, 26 “empezó a hacer mal ajustes”), que desemboca en la cesión de las tierras a los bancos. También cita la expropiación por el Estado frente a la subversión (secuencia 27). Podemos añadir, a la luz de la historia económica del país, algunos elementos al conjunto de factores que explican el fin del latifundio en Cahabón: las crisis del precio del café, y el desarrollo de la cría de ganado impulsada por la demanda de carne de Estados Unidos. Ésta necesita menos mano de obra, lo que refuerza la expulsión de los colonos.

\section{Subversión versus lucha política y jurídica}

Se nota entonces una diferencia radical entre los dos relatos en cuanto a la época y a la caracterización del conflicto de tierras: Amílcar describe un momento de subversión, mientras Martín detalla una larga lucha jurídica y política. El evento desencadenador de la narrativa de Martín ocurre -pudimos establecerlo gracias a los archivos-durante la primavera democrática, así como lo demuestran las fechas de los primeros procesos judiciales que enfrentan a Marcelino Xol con Benjamín Champney (AGCA 1949, 1951). En efecto, en 1949, el régimen democrático emite el Código del Trabajo, que plantea que cualquier trabajo tiene que ser pagado en moneda nacional. Frente al reclamo de los sueldos en procesos jurídicos, Champney reacciona haciendo procesos por "invasión de tierras", argumentando que Marcelino Xol, al negarse a trabajar en la plantación, ha perdido su derecho a vivir en su predio (Figura 1). Puesto que los propietarios no pueden pagar los sueldos, estos procesos desembocan en concesiones de tierras. De modo que para los q'eqchi'es, la Reforma agraria de 1952 sólo valida los resultados de los trámites jurídicos que ya se habían llevado a cabo (véase también Grandin 2004). Podemos subrayar que el enfrentamiento legal sobre la cuestión del trabajo no pagado sigue hasta 1965 (AGCA 1965), cuando algunos ladinos atacan a Marcelino Xol por extorsiones (ya que recolecta fondos en las aldeas en plena campaña electoral), mientras Marcelino Xol denuncia al alcalde por trabajo forzado en su propiedad privada (Figura 1). La evocación por Martín de las manifestaciones permite subrayar además la dimensión política de las acciones de su abuelo.

Complementando la perspectiva nacional sobre el conflicto, en la cual los historiadores subrayan el efecto acelerador del surgimiento de las guerrillas en los años 1960 y 1970 en una configuración compleja de protagonistas como la oligarquía, las iglesias, los militares y los movimientos indígenas construyéndose entre comunidades esparcidas (Le Bot 1992; Bataillon 2003), esta narrativa revela que, a nivel local, la lucha de los colonos q'eqchi'es en los años 1960 y 1970 se inscribe en la continuidad de los años 1940 y 1950, con una agravación progresiva de la violencia. Experimentan condiciones cada vez más duras, y encarcelamientos arbitrarios (Martín, secuencia 20). La lucha política se ve rechazada hacia la clandestinidad por la dictadura militar y los trámites jurídicos ya no dan resultados: de hecho, aunque Martín insiste con razón en que su abuelo no era comunista (secuencia 27), se fue acercando 
a personalidades de la guerrilla (Grandin 2004; Bergeret 2012, p. 313-314, 321, 323-326 para una discusión más precisa acerca de los compromisos de Marcelino Xol en partidos políticos).

Así, los períodos de antagonismo intenso simbolizados en cuadros rojos en la figura 1 tienen situaciones temporales muy diferentes según las diferentes perspectivas. Cabe aquí poner de relieve el tipo de tiempo que Martín construye en su relato. En la medida en que no recurre a ningún hito, evento ni contexto de dimensión nacional, y ya que su relato no tiene anclaje en años precisos del siglo Xx, se centra en un espacio-tiempo "cahabonero", aislado y cerrado. La lucha jurídica y política local puede constituir la etapa que permite, esta vez, revertir el ciclo multi-secular entre "viejos tiempos injustos" y nuevas épocas "sin miedo" (secuencia 39), e inscribir al abuelo en la serie de los héroes del territorio (ver tabla 2$)^{20}$.

En la versión de Amílcar, la época de la primavera democrática tampoco se subraya (véanse cómo difieren las secuencias entre la historia nacional y las versiones locales, Figura 1): no se menciona, como si esta época sólo se caracterizara por un periodo de paz y crecimiento de la finca. Este silencio se podría explicar por el hecho de que se prefiera ocultar este momento; pero también indica que la primavera democrática (1944-1954) tuvo en definitiva poca incidencia estructural en un sistema local muy cerrado. Las concesiones de tierras no representaron una ruptura histórica larga, puesto que las tierras pudieron ser recuperadas unos meses después -gracias a la anulación de la reforma agraria por el régimen militar- o fueron compradas de nuevo a sus nuevos propietarios por un precio barato (secuencia 13). Otro aspecto silenciado por Amílcar es el apoyo que encuentran los colonos entre los abogados ladinos (Martín, secuencia 17). Cabe mencionar también que ciertos testimonios q'eqchi'es y ladinos (Bergeret 2012, p. 697-706) destacan que otros propietarios ladinos, rivales de Champney, usaron todas las estrategias posibles para desestabilizarle, apoyando por ejemplo la lucha jurídica y política de los colonos (Grandin 2004).

Por fin, Amílcar oculta en gran parte la guerra (en realidad, se interrumpe a sí mismo justo cuando está por hablar de ella o de la "guerrilla", secuencia 28). Da a entender que la "subversión" cobró poca fuerza en Cahabón, empezando solamente en los años 1970 (cuando ya las fincas estaban en la crisis económica).

20. Ahora bien, existen sin embargo puntos de referencias a una cronología reciente: el nombramiento de personas (ciertos propietarios, alcaldes y asesinos secuencias 18, 30) conocidas por todos los cahaboneros todavía. Este anclaje indirecto en años precisos tiene una función de denuncia y de motor para las nuevas luchas de hoy (quiere designar las personas responsables, según él, de la desaparición de su abuelo, que todavía no ha sido investigada). Por lo tanto, encaja también en su visión cíclica de la historia: como nos lo dijo en otra oportunidad, ahora se abre una nueva era del calendario maya que será un ciclo de "justicia". 
Acredita la tesis de la "manipulación" de los colonos desde afuera ("invadió", secuencia 27), asimismo explica que los colonos obedecían y no iban a trabajar por temor a los movimientos de subversión. Sin embargo, Amílcar precisa que el problema central y legítimo era la cuestión del pago del trabajo (secuencia 27).

Por su lado, Martín no desarrolla en este primer relato las persecuciones sufridas por los civiles, ni las profundas divisiones que ocurrieron dentro de las comunidades en relación con la lucha por la tierra, ni tampoco las acciones de la guerrilla (en particular, el asesinato de uno de los mayores propietarios cahaboneros, acusado de estar implicado en la desaparición de Marcelino Xol).

\section{¿Tiempos mejores?}

Ya hemos evocado el proceso de adquisición de las tierras por los colonos como un intento de "pago para renacer". Entre los q'eqchi'es, muy pocos hablan espontáneamente de la compra de la tierra. A partir de 1979, frente a la represión masiva, las comunidades aceptaron poco a poco la solución propuesta por el Estado, y pagaron la tierra mediante un proceso administrativo largo y tortuoso organizado por el INTA que duró más de dos décadas, y sigue hoy con la parcelación (la lleva a cabo el nuevo organismo estatal Fondo de Tierras que reemplazó el INTA en el año 2000). Dicha compra de tierra se asocia, en los recuerdos de los q'eqchi'es, al hecho de participar obligatoriamente en los programas de plantaciones comerciales, como el cacao, el café y el cardamomo. Martín termina su relato diciendo que la lucha campesina les permitió mejorar su situación, acabar con el miedo, y recuperar la dignidad (Martín, secuencias 38-39): los antiguos colonos se han vuelto pequeños agricultores, propietarios de sus parcelas. Sin embargo, los resultados de la guerra suscitan sentimientos mezclados y contradictorios entre otros q'eqchi'es a quienes interrogamos. Este desencanto, silenciado por Martín, se entiende si analizamos el balance de la compra de la tierra. En 2003, las grandes propiedades de más de 45 hectáreas ocupan todavía más del $43 \%$ de la superficie de Cahabón. Las propiedades más pequeñas, de menos de 7 hectáreas, representan el $64 \%$ de las propiedades y abarcan el $20 \%$ del territorio. Estas familias no pueden asegurar su autosuficiencia. La tasa de pobreza en Cahabón es de 93\% y la desigualdad de ingresos (índice de Gini) es de 0,627 . Las desigualdades y la inseguridad alimenticia y económica resultan muy fuertes. Las crisis de los precios de los productos agrícolas, las alteraciones climáticas, la demografía y la presión sobre una tierra muy erosionada están hipotecando el modo de vivir de los cahaboneros.

Entre los ladinos, la venta de tierra se considera una puesta en conformidad con nuevos derechos: "Ya vinieron otras generaciones, ya había cambio, ya no se podía trabajar así con ellos. [...] [Se decía:] "la tierra es de ellos, ellos tienen derecho", aunque prácticamente esa tierra era de ellos porque la trabajaban [...]. Entonces para evitarnos problemas con la gente, las leyes y todo, mejor vender el terreno" dice Lucy, una ladina del pueblo. 
En efecto, Amílcar constató, más adelante en nuestra discusión: "la situación va a ser otra, porque se va a voltear la tortilla y estamos en este punto. Y ahorita la gente no se deja engañar. Ya la gente ha despertado, ya las escuelas gracias a Dios han hecho su parte, ya hay más civilización, ya los derechos humanos los entienden. Ahorita la gente come y no se subleva, y ya saben discutir sus derechos. En aquel tiempo, no".

De esta forma, el tiempo de la finca se inscribe dentro del tiempo linear del progreso de la civilización. Su motor es el movimiento de progreso social y moral: la finca se ha apoyado en una mano de obra "pisoteada" (secuencia 19), pero la dinámica histórica ha permitido, en una nueva etapa, que dicha mano de obra integre y asimile la civilización. Notamos el uso de una imagen de inversión con la "vuelta de la tortilla": de hecho, el avance histórico, es, para los ladinos cahaboneros, paradójico: se vive como una mejora general de las condiciones de vida, y a la vez, se siente la pérdida de una edad de oro durante la cual el grupo ladino era privilegiado.

\begin{tabular}{|c|c|c|}
\hline & $\begin{array}{c}\text { La saga de los Champney } \\
\text { por Amílcar }\end{array}$ & $\begin{array}{c}\text { La lucha contra la "Asyent" } \\
\text { por Martín }\end{array}$ \\
\hline $\begin{array}{l}\text { Estatuto } \\
\text { social }\end{array}$ & $\begin{array}{l}\text { Relato a la etnógrafa extranjera. } \\
\text { Conversación inter-individual } \\
\text { Objetivo de dar } \\
\text { un testimonio directo } \\
\text { de la historia de la finca mayor } \\
\text { de Cahabón. } \\
\text { ¿Género narrativo en contexto } \\
\text { familiar? }\end{array}$ & $\begin{array}{c}\text { Narrativa a la etnógrafa extranjera } \\
\text { Conversación inter-individual } \\
\text { Objetivo de dar testimonio } \\
\text { de la vida heroica del abuelo. }\end{array}$ \\
\hline $\begin{array}{l}\text { Punto } \\
\text { de vistadel } \\
\text { narrador }\end{array}$ & $\begin{array}{c}\text { Punto de vista interno } \\
\text { Intención de construir una historia } \\
\text { establecida. } \\
\text { Descripción de la fuente de } \\
\text { información autobiográfica o } \\
\text { familiar (el padre) como garantía. } \\
\text { Saber extenso sobre los personajes } \\
\text { (sentimientos y palabras de los } \\
\text { Champney) } \\
\text { Posición parcial y matizada } \\
\text { (admiración de la finca, silencio } \\
\text { sobre la lucha campesina local, } \\
\text { calificación del trabajo en la finca } \\
\text { como explotación) }\end{array}$ & $\begin{array}{c}\text { Interno } \\
\text { Intención de construir una historia } \\
\text { establecida } \\
\text { No explica quién le contó la } \\
\text { historia } \\
\text { Saber extenso sobre los } \\
\text { personajes (sentimientos de } \\
\text { diferentes grupos, pero el relato } \\
\text { privilegia un grupo) } \\
\text { Posición militante (un grupo } \\
\text { "bueno" enfrentando injusticias) }\end{array}$ \\
\hline
\end{tabular}




\begin{tabular}{|c|c|c|}
\hline $\begin{array}{c}\text { Tema y } \\
\text { Personajes }\end{array}$ & $\begin{array}{l}\text { La dinastía de los propietarios } \\
\text { Relación económica y social entre } \\
\text { el propietario y los trabajadores } \\
\text { Personajes: el dueño, } \\
\text { el administrador, el mayordomo, } \\
\text { las autoridades, los alcaldes } \\
\text { / } \\
\text { La gente, los empleados, } \\
\text { los obreros, los colonos, las } \\
\text { familias, el alcalde auxiliar, las } \\
\text { comunidades }\end{array}$ & $\begin{array}{l}\text { Lucha política entre "nosotros" } \\
\text { y los propietarios. } \\
\text { Personajes: Eb'li kristiaan } \\
\text { (la gente), li qas qitzin (nuestros } \\
\text { hermanos), li k'aleb'aal (las } \\
\text { aldeas), laa'o li ne'b'a'o } \\
\text { (nosotros los pobres) } \\
\text { / } \\
\text { Champney, li patrón, laj asyent } \\
\text { (los propietarios de Hacienda), li } \\
\text { alcalde, eb'li ladino, eb'li militar. }\end{array}$ \\
\hline Tiempos & $\begin{array}{l}\text { El siglo xx (con indicaciones } \\
\text { cronológicas precisas) } \\
\text { Una línea temporal paradójica de } \\
\text { civilización que pasa por el fin } \\
\text { de la edad de oro de la Finca (un } \\
\text { ciclo económico encajado en la } \\
\text { visión progresista de la historia, } \\
\text { hacia la integración e asimilación } \\
\text { de los antiguos colonos). }\end{array}$ & $\begin{array}{l}\text { Viejos tiempos de li Asyent (sin } \\
\text { indicaciones cronológicas precisas) } \\
\text { Un episodio en la historia } \\
\text { cíclicade intrusiones injustas } \\
\text { y rechazadas por héroes, } \\
\text { exclusivamente cahabonera. }\end{array}$ \\
\hline Intriga & $\begin{array}{l}\text { La sucesión de generaciones } \\
\text { de propietarios. } \\
\text { Creación } \rightarrow \text { crecimiento } \\
\rightarrow \text { el accidente de avión y la mala } \\
\text { gestión de los herederos } \rightarrow \text { crisis } \\
\quad \rightarrow \text { fin de la Finca }\end{array}$ & $\begin{array}{l}\text { Territorio establecido en la } \\
\text { sujeción } \rightarrow \text { caída } \rightarrow \text { denuncia } \\
\text { del robo en el funcionamiento del } \\
\text { territorio por el héroe } \rightarrow \text { lucha } \\
\quad \rightarrow \text { sanción-sacrificio. }\end{array}$ \\
\hline
\end{tabular}

Tabla 2 - Comparación entre las dos narrativas sobre la Hacienda.

\section{Conclusión}

Las narrativas presentadas aquí han permitido observar cómo, frente a la etnógrafa, los actores juegan entre géneros narrativos, para expresar su relación con los diferentes tiempos del pasado, resaltar ciertos eventos y personajes, y construir así una memoria que da sentido al mundo actual. El género de "las historias" sigue muy presente hoy en día, permitiendo arraigar el presente en edades primordiales o a-históricas.

Sin embargo, la guerra introdujo claramente una ruptura profunda ("se cambió el tiempo" constata González 2002), y la impunidad, la inseguridad económica, las decepciones múltiples en cuanto a avances sociales y políticos desde la transición democrática, hacen muy difícil la construcción de una narrativa consensual, establecida y reconocida respecto a la historia reciente. Cuesta 
"dar sentido" al pasado reciente y encontrar un género narrativo adecuado. En este contexto, el relato de Martín juega con los géneros institucionalizados y construye una doble conexión entre el género de "las historias" y el género de "lo padecido": por un lado, permite expresar lo sufrido, la historia íntima y, por otro lado, explota los viejos esquemas del cambio en el mundo. Desde su estatuto social muy especial (siendo Martín un hombre bastante joven, que vive en la ciudad, muy escuchado sin embargo en el área rural por su actividad de médico y de locutor de radio), negándose a conformarse con la victimización del pueblo q'eqchi', crea una versión militante y heróica del rechazo de un propietario injusto y de la recuperación de dignidad. La comparación con la versión de Amílcar revela las especificidades de sus argumentos, de sus silencios y de sus lecturas radicalmente distintas de los periodos históricos.

Cuando Martín contó la historia de su abuelo, terminó explicando como él mismo se había comprometido en la vida política local desde los años 1980, para seguir con las luchas de su antepasado. Invocaba regularmente el nombre de Marcelino Xol y la necesidad para los cahaboneros actuales de ser dignos de sus antepasados, ya que siempre llegan nuevos intrusos y nuevos desafíos. Así, lo que une "las historias" y la narrativa de Martín -y podríamos añadir, la actividad ritual muy intensa en Cahabón- es aseguradamente su función soteriológica, es decir de salvación y de resurrección (Bastide 1968, p. 1061). Martín, en sus narrativas como en sus acciones, se esfuerza para que se mantenga una continuidad con los antepasados, para que los héroes sacrificados del pasado renazcan o que por lo menos, queden vivos en la memoria y den una inspiración para seguir el esfuerzo hacia la autonomía.*

* Manuscrit reçu en mai 2015, accepté pour publication en octobre 2016.

Este artículo forma parte del número especial Compases y texturas del tiempo entre los mayas: lo dicho, lo escrito, lo vivido.

Agradecimientos - Agradezco a Valentina Vapnarsky y a los dictaminadores, asi como a los encargados del trabajo editorial, por su valiosa ayuda en la redacción de este artículo.

\section{Referencias citadas}

Adam Jean-Michel y Ute HeIDmann

2009 Le texte littéraire. Pour une approche interdisciplinaire, Academia Bruylant, Louvain.

AgCA (Archivo General de Centro América)

1949 "Reo: Marcelino Xol; Delito: Daños; Ofendido: Benjamin Champney", Archivo General de Centro América, Juzgado de primera instancia de Cobán AGCA-J-AV 107 leg 55 Exp. 4371. 
Narrativas del conflicto y construcciones del pasado entre los q'eqchi'es

1951 "Reo: Marcelino Xol; Delito: usurpación y daños; Ofendido: Benjamin Champney", Archivo General de Centro América, Juzgado de primera instancia de Cobán, AGCA-J-AV107 leg 57D Exp. 563.

1965 "Reos: Marcelino Xol, Tomás Pop Ochoa, Manuel Choc Hoo, Rafael Ixixm Chun, Pedro Quej, Francisco Caal Coc, Diego Caal; Delito: Estafa; Ofendidos: Bernabe Bol Choc y Compañeros", Archivo General de Centro América, Juzgado de primera instancia de Cobán, AGCA-J-AV 107 leg 71C Exp. 4674.

AK' KUTAN

1999 Q'eelink ut li yu'amil na'leb'. Li loq'laj k'anjel chi rix li mayejak sa'xyanqeb' laj q'eqchi', Ak' kutan, Cobán.

AKKEREN Ruud Van

2000 Place of the Lord's Daughter. Rab'inal, its History, its Dance Drama, Research school CNWS, school of Asian, African and Amerindian Studies, Universiteit Leiden, Leiden.

Almg (Academia de lenguas mayas de Guatemala)

2004 Xtusulal aatin sa' Q'eqchi', Vocabulario q'eqchi', Academia de lenguas mayas de Guatemala, Guatemala.

2008 Molob'aal aatin q'eqchi', Academia de lenguas mayas de Guatemala, Guatemala.

Argueta Amílcar

2005 En la Tierra de los brujos, Edición propia.

BAKHTINE Mikhaïl

1984 "Les genres du discours", in Mikhail Bakhtine, Esthétique de la création verbale, Paris, Gallimard, p. 263-308 (texte de 1952-1953, publié en 1979, traduction française 1984)

BASTIDE Roger

1968 "La mythologie", in Jean Poirier (dir.), Ethnologie générale, Gallimard, Paris, p. 1037-1090.

BATAILlON Gilles

2003 Genèse des guerres internes en Amérique centrale, Les Belles Lettres, Paris.

BeCQuelin Aurore, Antoinette Molinié (éd.)

1993 Mémoire de la tradition, Société d'ethnologie, Nanterre.

Bergeret Agnès

2012 La quête d'autonomie des paysans mayas-q'eqchi' de Cahabón (Guatemala), 1944-2011. Trois perspectives sur les conflits de terre et les politiques de développement agricole [en ligne], thèse de doctorat en anthropologie, IHEAL-Université Paris 3-Sorbonne Nouvelle, Paris, https://tel.archives-ouvertes.fr/tel-01127078

BRAAKHUIS Hyaccinthus E.

2010 Xbalanque's Marriage. A Commentary on the Q'eqchi' Myth of Sun and Moon, Universiteit Leiden, Leiden.

BRICKER Victoria

1981 The Indian Christ, the Indian King. The Historical Substrate of Mayan Myth and Ritual, University of Texas Press, Austin. 
BuRKITT Robert

1917-1920 “The Hills and the Corn”, University of Pennsylvania (University Museum Anthropological publications 8, no 2), p. 196-226.

CAmbranes Julio Castellanos

1996 Café y campesinos. Los orígenes de la economía de plantación moderna en Guatemala, 1853-1897, Catriel, Madrid.

Cruz Torres Mario Enrique

1978 Rubelpec, cuentos y leyendas, Editorial del Ejército, Guatemala.

Cuz Agustín

2001 Li loq'laj yu'amej, Academia de lenguas mayas de Guatemala, Guatemala. DANIEN Elin

2005 Maya Folktales from the Alta Verapaz, University of Pennsylvania Museum of Archaeology and Anthropology, Philadelphia.

Estrada Monroy Agustín

1990 Vida esotérica maya-k'ekchi. Ministerio de Cultura y Deportes, Guatemala.

GonZÁlez Matilde

2002 Se cambió el tiempo. Conflicto y poder en territorio k'iche' 1880-1996. AVANCSO Cuadernos de investigación, $n^{\circ} 17$, Guatemala.

GRANDIN Greg

2001 Denegado en su totalidad, AVANCSO, Guatemala.

2004 The Last Colonial Massacre. Latin America in the Cold War, University of Chicago Press, Chicago.

Gutierrez-Estevés Manuel

1998 "Plurality of Perspectives and Subjects in the Literary Genres of the Yucatec Maya”, American anthropologist, 100 (2) p. 309-325.

HuEt Alfonso

2006 Xooxkol li loq'laj tzuul, loq'laj k'iche', ADICI Wakliiqo, Cobán.

Kockelman Paul

2007 "Meaning and Time. Translation and Exegesis of a Mayan Myth", Anthropological Linguistics, 49 (3-4), p. 308-387.

2017 “Time and Replacement among the Q'eqchi'-Maya”, Journal de la Société des Américanistes, special issue, ("Measures and textures of time among

Le Bot Yvon the Mayas") [en línea]), 2017.

1992 La guerre en terre maya. Communauté, violence et modernité au Guatemala (1970-1992), Karthala, Paris.

Nora Pierre

1978 "La mémoire collective", in Jacques Le Goff (dir.), La nouvelle histoire, Retz-CEPL, Paris, p. 398-401.

ODHAG-REHMI

1998 Guatemala; Nunca más. Oficina de derechos humanos del Arzobispado PAREDES Carlos de Guatemala-Tercera prensa - Hirugarren prentsa, Guatemala.

2006 Te llevaste mis palabras. Efectos psicosociales de la violencia política en comunidades del pueblo q'eqchi', F\&G editores y Equipo de estudios comunitarios y acción psicosocial, Guatemala. 
Narrativas del conflicto y construcciones del pasado entre los q'eqchi'es

Propp Vladimir

$1970 \quad$ Morphologie du conte, Seuil, Paris (traduction T. K. Derrida).

RABATEL Alain

1997 Une histoire du point de vue, Centre d'étude linguistique des textes et des discours, Metz.

Riceur Paul

1983, 1984, 1985 Temps et Récit, Tome 1, 2, 3, Seuil, Paris.

2003 La mémoire, l'histoire, l'oubli, Seuil, Paris.

TODOROv Tzvetan

1978, Les genres du discours, Seuil, Paris.

VAPNARSKY Valentina

2001 "Cambio y continuidad en las concepciones históricas mayas: estrategias discursivas y constitución de la memoria colectiva entre los mayas macehuales de Quintana Roo", in Ueli Hostettler y Mathew Restall (eds), VEYNES Paul Maya Survivalism, vol. 12, Verlag Anton Saurwein, Germany, p. 175-190.

1971 Comment on écrit l'histoire, Seuil, Paris.

WAGNER Regina

1996 Los Alemanes en Guatemala, 1820-1944, Afanes, Guatemala.

Wolf Eric y Sidney MinTz

1975 "Haciendas y plantaciones en Mesoamérica y las Antillas", in Enrique Florescano (ed.), Haciendas, latifundios y plantaciones en América latina, Siglo Veintiuno, México, p. 493-531. 
